\title{
Formation of amines: hydrogenation of nitrile and isonitrile as selective routes in the interstellar medium
}

\author{
T. Nguyen ${ }^{1,2}$, I. Fourré ${ }^{3}$, C. Favre ${ }^{4}$, C. Barois ${ }^{3}$, E. Congiu ${ }^{1}$, S. Baouche ${ }^{1}$, J.-C. Guillemin ${ }^{5}$, \\ Y. Ellinger ${ }^{3}$, and F. Dulieu ${ }^{1}$
}

\author{
${ }^{1}$ Université de Cergy-Pontoise, Sorbonne Université, Observatoire de Paris, Université PSL, CNRS, LERMA, \\ 95000 Cergy-Pontoise, France \\ e-mail: francois.dulieu@obspm.fr \\ ${ }^{2}$ Institute of Low Temperature Science, Hokkaido University, Sapporo, Hokkaido 060-0819, Japan \\ e-mail: nguyenthanh@lowtem.hokudai.ac.jp \\ ${ }^{3}$ Sorbonne Université, CNRS, Laboratoire de Chimie Théorique, LCT, 75005 Paris, France \\ ${ }^{4}$ Univ. Grenoble Alpes, CNRS, IPAG, 38000 Grenoble, France \\ e-mail: cecile.favre@univ-grenoble-alpes.fr \\ ${ }^{5}$ Univ. Rennes, Ecole Nationale Supérieure de Chimie de Rennes, CNRS, ISCR - UMR 6226, 35000 Rennes, France
}

Received 25 January 2019 / Accepted 13 April 2019

\begin{abstract}
Context. Beyond $\mathrm{NH}_{3}$, only one primary alkylamine, $\mathrm{CH}_{3} \mathrm{NH}_{2}$, has been identified in the interstellar medium and the reason why is still not understood: its formation could occur in the gas phase or in icy environments.

Aims. To consider any possible difference between the formation of primary and secondary amines, we studied the hydrogenation processes of $\mathrm{CH}_{3} \mathrm{CN}$ and $\mathrm{CH}_{3} \mathrm{NC}$, which would lead to the simple primary $\mathrm{CH}_{3} \mathrm{CH}_{2} \mathrm{NH}_{2}$ and secondary $\mathrm{CH}_{3} \mathrm{NHCH}_{3}$ amines, respectively. Methods. Experimentally, the hydrogenation of $\mathrm{CH}_{3} \mathrm{CN}$ and $\mathrm{CH}_{3} \mathrm{NC}$ was carried out under ultra-high vacuum, using two beamlines to inject the nitrile/isonitrile and $\mathrm{H}$ onto substrate surfaces of gold or water ice. The reactions were monitored using infrared spectroscopy and the products were followed by mass spectrometry. Theoretically, the energetics of the hydrogenation paths were determined using the M06-2X functional after benchmarking against post Hartree-Fock procedures. Meanwhile, a survey of the high-mass star forming region W51/e2 has been performed.

Results. Following co-deposition of $\mathrm{CH}_{3} \mathrm{CN}$ and $\mathrm{H}$, we show that these species do not react together between 10 and $60 \mathrm{~K}$. For $\mathrm{CH}_{3} \mathrm{NC}$ we found that the hydrogenation process works all the way through the $\mathrm{CH}_{3} \mathrm{NHCH}_{3}$ end product; we also identified the $\mathrm{CH}_{3} \mathrm{NCH}_{2}$ intermediate together with side products, $\mathrm{CH}_{4}$ and $\mathrm{HCN}$, showing that the isonitrile backbone is breaking. These results are consistent with the calculations of a high barrier on the first hydrogenation step for $\mathrm{CH}_{3} \mathrm{CN}$ and a lower barrier for $\mathrm{CH}_{3} \mathrm{NC}$.

Conclusions. The formation of $\mathrm{CH}_{3} \mathrm{CH}_{2} \mathrm{NH}_{2}$ by hydrogenation of $\mathrm{CH}_{3} \mathrm{CN}$ appears rather unlikely in both the gas phase and ice environment whereas that of $\mathrm{CH}_{3} \mathrm{NHCH}_{3}$ is a clear possibility. The limiting factor appears to be the efficiency of the tunneling effect through the first activation barrier on the reaction paths. More surveys are required for further insight into the search for amines.
\end{abstract}

Key words. ISM: molecules - astrochemistry

\section{Introduction}

More than 200 species have been detected so far in the interstellar medium (ISM) and circumstellar shells including complex molecules (COM) from 6 to 13 atoms (McGuire 2018) ${ }^{1}$. On the other hand, observing isomers is a good way to trace the origin of molecules in the ISM. Indeed excluding diatomic molecules, $30 \%$ of all interstellar molecules have isomeric counterparts (Remijan et al. 2005). Therefore, the formation and evolution of interstellar clouds and the stars they generate can be explored through isomer comparison studies.

Many saturated and alkynyl cyanides have been detected in the ISM while only ammonia, methylamine, and aminoacetonitrile were found as amines. For example, there were methyl cyanide (or acetonitrile, $\mathrm{CH}_{3} \mathrm{CN}$ ), ethyl cyanide $\left(\mathrm{CH}_{3} \mathrm{CH}_{2} \mathrm{CN}\right.$ ), $\mathrm{n}$ - and iso-propyl cyanide (n-(iso-) $\mathrm{C}_{3} \mathrm{H}_{7} \mathrm{CN}$ ), vinyl cyanide

\footnotetext{
1 See also https://cdms .astro.uni-koeln.de/ and/or http:// www. astrochymist.org/astrochymist_ism.html
}

$\left(\mathrm{CH}_{2} \mathrm{CHCN}\right)$, and cyanoacetylene $\left(\mathrm{HC}_{3} \mathrm{~N}\right)$, which are $\mathrm{COMs}$ detected in many regions of the ISM (Solomon et al. 1971; Johnson et al. 1977; Gardner \& Winnewisser 1975; Belloche et al. 2009, 2014; Turner 1971; Friedel et al. 2004; Nummelin et al. 1998). Recently a first example of a $\mathrm{C} \equiv \mathrm{N}$ group conjugated to an aromatic ring, benzonitrile $\mathrm{C}_{6} \mathrm{H}_{5} \mathrm{CN}$, has been identified (McGuire et al. 2018) in TMC-1, showing a new structural possibility for a hydrocarbon substituent. On the other hand, only three organic isocyanides were observed. For instance, isocyanoacetylene $\left(\mathrm{HC}_{2} \mathrm{NC}\right)$, which is an isomer of cyanoacetylene (HCCCN, a very abundant interstellar species), has been detected in TMC-1 (Kawaguchi et al. 1992); HNC has been found in W51 (Zuckerman et al. 1972) and methyl isocyanide $\left(\mathrm{CH}_{3} \mathrm{NC}\right)$ has been tentatively detected toward Sgr B2 for the first time by Cernicharo et al. (1988). $\mathrm{CH}_{3} \mathrm{NC}$ was previously possibly detected in the cold dark cloud TMC-1 (Irvine \& Schloerb 1984) and has been confirmed in other cold clouds (e.g., L1544) in the hot cores of Orion KL (Remijan et al. 2005; Cernicharo et al. 1988; López et al. 2014; Jiménez-Serra et al. 2016) and in 
the Horsehead photodissociation region (PDR) by Gratier et al. (2013).

Intuitively proposed, the formation of amines by reduction of nitriles is not obvious. The best examples are the case of abundant $\mathrm{CH}_{3} \mathrm{CN}$ and $\mathrm{CH}_{3} \mathrm{CH}_{2} \mathrm{CN}$ (Belloche et al. 2016; Margulès et al. 2016, respectively). The bis ${ }^{13} \mathrm{C}$ isotopolog of $\mathrm{CH}_{3} \mathrm{CN}$ and the three bis ${ }^{13} \mathrm{C}$ isotopologs of $\mathrm{CH}_{3} \mathrm{CH}_{2} \mathrm{CN}$ were found to be $\sim 470$ and $\sim 800$ times less abundant than their parent compounds, respectively, while attempts to detect ethyl amine $\left(\mathrm{CH}_{3} \mathrm{CH}_{2} \mathrm{NH}_{2}\right)$ and propylamine $\left(\mathrm{CH}_{3} \mathrm{CH}_{2} \mathrm{CH}_{2} \mathrm{NH}_{2}\right)$ failed. On the basis of the nitriles ( $\sim 4$ Debye) and amines ( $\sim 1$ Debye) dipole moments, we can estimate that amines are at least about 30-50 times less abundant than the corresponding nitriles.

To limit the number of possible reactive sites, we consider only the possibility for hydrogenation of a single $\mathrm{C} \equiv \mathrm{N}$ functional group. The number of such species with saturated substituents is much more limited. It is reduced to $\mathrm{CH}_{3} \mathrm{CN}$ (Solomon et al. 1971), $\mathrm{CH}_{3} \mathrm{CH}_{2} \mathrm{CN}$ (Johnson et al. 1977), n- $\mathrm{C}_{3} \mathrm{H}_{7} \mathrm{CN}$ (Belloche et al. 2009), and $\mathrm{i}-\mathrm{C}_{3} \mathrm{H}_{7} \mathrm{CN}$ (Belloche et al. 2014) for nitriles and only to $\mathrm{CH}_{3} \mathrm{NC}$ (Cernicharo et al. 1988) for isonitriles. In what follows we focus on the only example with the nitrile/isonitrile group attached to the same hydrocarbon substituent, that is $-\mathrm{CH}_{3}$.

For typical dense cloud conditions, theoretical calculations of Defrees et al. (1985) estimated the ratio of $\mathrm{CH}_{3} \mathrm{NC} / \mathrm{CH}_{3} \mathrm{CN}$ to be in the range 0.1-0.4. However, Cernicharo et al. (1988) deduced from their observations an abundance ratio of $\sim 0.03$ 0.05 , showing that $\mathrm{CH}_{3} \mathrm{CN}$ is an order of magnitude higher than previous estimates. Later, Gratier et al. (2013) found, according to their observations in the Horsehead region, an abundance ratio $\mathrm{CH}_{3} \mathrm{NC} / \mathrm{CH}_{3} \mathrm{CN}$ in agreement with estimations of Defrees, at least at the PDR position where a high UV irradiation is at work.

The difference in abundance of stable isomers in the same environment has been tentatively explained by their different intrinsic stabilities (Lattelais et al. 2009) and/or by their different binding energies to solid particles because one of the isomers is more effectively trapped on dust grains, and so depleted from the gas phase (Lattelais et al. 2011). To check this possibility, Bertin et al. (2017) have done a laboratory study showing that the adsorption energy of $\mathrm{CH}_{3} \mathrm{CN}$ on hydroxylated surfaces is higher than the adsorption energy of $\mathrm{CH}_{3} \mathrm{NC}$, which rules out the hypothesis of a lack of $\mathrm{CH}_{3} \mathrm{NC}$ in the gas phase because of a very high binding energy. So the origin of the low isomeric ratios should have entirely a chemical origin.

Hudson \& Moore (2004) bombarded a film of $\mathrm{CH}_{3} \mathrm{CN}$ with UV photons and energetic protons and found that $\mathrm{CH}_{3} \mathrm{CN}$ can partially isomerize to $\mathrm{CH}_{3} \mathrm{NC}$, indicating a possible direct chemical link between the two isomers in the solid phase. Recently Mencos \& Krim (2016) reported that $\mathrm{CH}_{3} \mathrm{CN}$ may react with ground state $\mathrm{N}$ atoms to form $\mathrm{CH}_{3} \mathrm{NC}$ and $\mathrm{CH}_{2} \mathrm{CNH}$ in the solid phase at temperatures ranging from 7 to $11 \mathrm{~K}$.

These laboratory results support the now large consensus that gas-phase chemistry alone cannot account for the diversity of complex organic molecules observed in the ISM and that solid-gas reactions, as well as chemical processes involving adsorbed or/and embedded partner, have to be taken into account. In that context interstellar grains play a crucial role. These small particles, most often covered with ices, may protect the molecules from the radiation field and, at the same time, play the role of a third body helping dissipation of the energy excess released by exothermic reactions. These particles may also provide the catalytic conditions to overcome activation barriers impeding reaction paths and directly contribute to the reaction budget.
The most efficient chemical transformation of the molecular mantle during its formation on grains is the hydrogenation. $\mathrm{H}$ atoms are always orders of magnitude more abundant than $\mathrm{N}$ atoms. According to the astrophysical conditions, the hydrogenation efficiency has been mostly studied at low temperatures ( $\sim 10 \mathrm{~K}$; Sandford et al. 2006). Hydrogenation drives the formation of many molecules in the solid state, from the simplest $\left(\mathrm{H}_{2}, \mathrm{H}_{2} \mathrm{O}\right)$ to the more complex such as formaldehyde $\left(\mathrm{H}_{2} \mathrm{CO}\right)$, methanol $\left(\mathrm{CH}_{3} \mathrm{OH}\right)$, hydroxylamine $\left(\mathrm{NH}_{2} \mathrm{OH}\right)$, formic acid $(\mathrm{HCOOH})$, ethanol $\left(\mathrm{CH}_{3} \mathrm{CH}_{2} \mathrm{OH}\right)$, or even formamide $\left(\mathrm{NH}_{2} \mathrm{CHO}\right.$ ) (Congiu et al. 2012; Minissale et al. 2016; Hiraoka et al. 2005; Watanabe et al. 2004; Ioppolo et al. 2011; Bisschop et al. 2007; Dulieu et al. 2019). Considering $\mathrm{C} \equiv \mathrm{N}$ containing species, the hydrogenation of $\mathrm{HCN} / \mathrm{HNC}$ has been looked at in the gas phase (Talbi \& Ellinger 1996; Talbi et al. 1996) and on HCN ice (Theulé et al. 2011). Full hydrogenation leads to the same end product, methylamine $\left(\mathrm{CH}_{3} \mathrm{NH}_{2}\right)$, that is the simplest and only aliphatic amine detected in the ISM (Kaifu et al. 1974). To our knowledge the hydrogenation of $\mathrm{CH}_{3} \mathrm{CN}$ and $\mathrm{CH}_{3} \mathrm{NC}$ has not yet been undertaken.

Nevertheless, selective destruction pathways of $\mathrm{CH}_{3} \mathrm{NC}$ relative to $\mathrm{CH}_{3} \mathrm{CN}$ would help astrochemical modelers to better reproduce observed values. This is the starting point of our study. We compare the hydrogenation of the two isomers on a surface maintained at low temperature $(8-40 \mathrm{~K})$, that is the reaction paths leading to the primary amine $\mathrm{CH}_{3} \mathrm{CH}_{2} \mathrm{NH}_{2}$ (path a) and to the secondary amine $\mathrm{CH}_{3} \mathrm{NHCH}_{3}$ (path b) as follows:

$$
\begin{array}{ll}
\mathrm{CH}_{3} \mathrm{CN} \stackrel{+4 \mathrm{H}}{\longrightarrow} \mathrm{CH}_{3} \mathrm{CH}_{2} \mathrm{NH}_{2} & \text { path a, } \\
\mathrm{CH}_{3} \mathrm{NC} \stackrel{+4 \mathrm{H}}{\longrightarrow} \mathrm{CH}_{3} \mathrm{NHCH}_{3} & \text { path b. }
\end{array}
$$

Our objective is to understand the details of the chemical network and the possible influence of water, which is the main constituent of molecular mantles on dust grains. The present work reports a concerted experimental/theoretical study coupled with recent observations toward a high-mass star forming region.

The article is organized as follows. In Sect. 2 we present the experimental setup, the protocol of the experiment, and the results obtained from the analysis of the quadrupole mass spectrometer (QMS) spectra as the reaction processes. In Sect. 3, we present the theoretical approach, starting by the benchmarking done to determine the more appropriate level of theory for this study. This is followed by the results of the calculations of enthalpies and activation barriers of the successive steps of the hydrogenation processes in the gas phase and the ice. Section 4 is a first report of the tentative search for molecules relevant to this study in the W51/e 2 region, using the IRAM 30 m telescope. In the last section, the theoretical and experimental results are compared and discussed with an emphasis on the possible implications on the abundances of amines in the ISM as shown by the results of the observational campaign.

\section{Experimental approach to hydrogenation processes}

\subsection{Experimental protocol}

The experiments were carried out with the VENUS experimental apparatus at the LERMA laboratory of the University of CergyPontoise. It consists of an ultra-high vacuum chamber (UHV) with a base pressure of $2 \times 10^{-10}$ mbar. The solid sample is a gold-plated surface that is maintained at low temperature using a helium closed-cycle cryostat. The surface temperature is controlled from 7 to $350 \mathrm{~K}$ thanks to a resistive heater. Absorbance 
spectra of adsorbates are recorded by Fourier Transform Reflection Absorption Infrared Spectroscopy (FT-RAIRS) from 750 to $4500 \mathrm{~cm}^{-1}$. Products (or residual reactants) are desorbed from the surface by using temperature programmed desorption (TPD). In our experiments, the surface temperature is raised from $10 \mathrm{~K}$ up to $260 \mathrm{~K}$. The heating ramp is kept constant with a value of $\beta=0.2 \mathrm{~K} \mathrm{~s}^{-1}$ and simultaneously desorbing species are detected through a QMS positioned in front of the surface.

The injection of atoms or molecules is carried out using a separate system consisting of four atomic or molecular beams. The gas passes through three chambers and into the main chamber via three aligned diaphragms. For this study we used only two beams: the central beam is used to inject $\mathrm{CH}_{3} \mathrm{NC}$ or $\mathrm{CH}_{3} \mathrm{CN}$ and the right beam is used to inject $\mathrm{H}$ atoms. The $\mathrm{H}_{2}$ flux entering the right beam source is controlled by an automated regulator by Bronkhorst High-Tech and is set to $10 \mathrm{sccm}^{2}$. A microwave discharge cavity is used to dissociate $\mathrm{H}_{2}$ flowing through a quartz tube (inner diameter $4 \mathrm{~mm}$ ), cooled with a continuous flow of compressed air at room temperature. The dissociation efficiency of $\mathrm{H}_{2}$ and $\mathrm{D}_{2}$ is 75 and $65 \%$, respectively. The dissociation efficiency, $\tau$, is calculated via the formula

$\tau=\frac{S_{\mathrm{OFF}}-S_{\mathrm{ON}}}{S_{\mathrm{OFF}}}$

where $S$ is the number of ion counts measured with the QMS in front of the sample when the discharge is switched off or on. $\mathrm{H}$ atoms produced in the plasma discharge are thermalized to approximately $300 \mathrm{~K}$ via collisions with the walls of the quartz tube, and then pass through the first diaphragm in an effusive regime. We previously determined that atoms are in their ground state (Amiaud et al. 2007; Congiu et al. 2009). Assuming that our flux is about $3 \times 10^{12}$ molecules $\mathrm{cm}^{-2} \mathrm{~s}^{-1}$ (i.e., an adsorbed species receives on average one atom every $300 \mathrm{~s}$ from the gas phase) and that the typical diffusion time from one site to another (at $10 \mathrm{~K}$ ) for $\mathrm{H}$ is within the timescale of one millisecond (or faster), the reactivity should be totally dominated by diffusive processes, that is the Langmuir-Hinshelwood mechanism. For the same reason, reacting atoms are mostly thermalized with the surface. It cannot be excluded, however, that the Eley-Rideal mechanism becomes non-negligible, especially when the surface temperature is above $20 \mathrm{~K}$, as $\mathrm{H}$ atoms begin to desorb very quickly. Therefore our experimental conditions mainly probe the reactivity of the minimum energy pathways.

$\mathrm{CH}_{3} \mathrm{NC}$ and $\mathrm{CH}_{3} \mathrm{CN}$ are liquid at room temperature and their saturation vapor is high enough so that their entrance flux can be manually regulated via a needle valve. The expansion chamber of the central beam is kept constant at a pressure of $1.5 \times 10^{-4}$ mbar. The length of the mean free flight of molecules in this chamber is about $2 \mathrm{~cm}$ before molecules are entering the second stage in which the pressure remains in the $10^{-7}$ mbar range. The third stage is kept in the $10^{-9}$ mbar range while the main chamber remains in the low $10^{-10}$ mbar range to achieve good vacuum conditions for cold surface experiments. Ten grams of $\mathrm{CH}_{3} \mathrm{NC}$ were synthesized by J.C. Guillemin in Rennes (Bertin et al. 2017) and traveled to Cergy in a frozen state. The experiments were performed twice. $\mathrm{CH}_{3} \mathrm{NC}$ was prepared performing freeze-thaw cycles in order to eliminate the residual atmospheric gases. We determined that the purity of $\mathrm{CH}_{3} \mathrm{CN}$ and $\mathrm{CH}_{3} \mathrm{NC}$ was $>98 \%$ (our maximum sensitivity), measured with the QMS positioned in front of the cold surface.

\footnotetext{
$21 \mathrm{sccm}=592 \mathrm{~m}^{3} \mathrm{~Pa} \mathrm{~s}^{-1}$ in SI units.
}
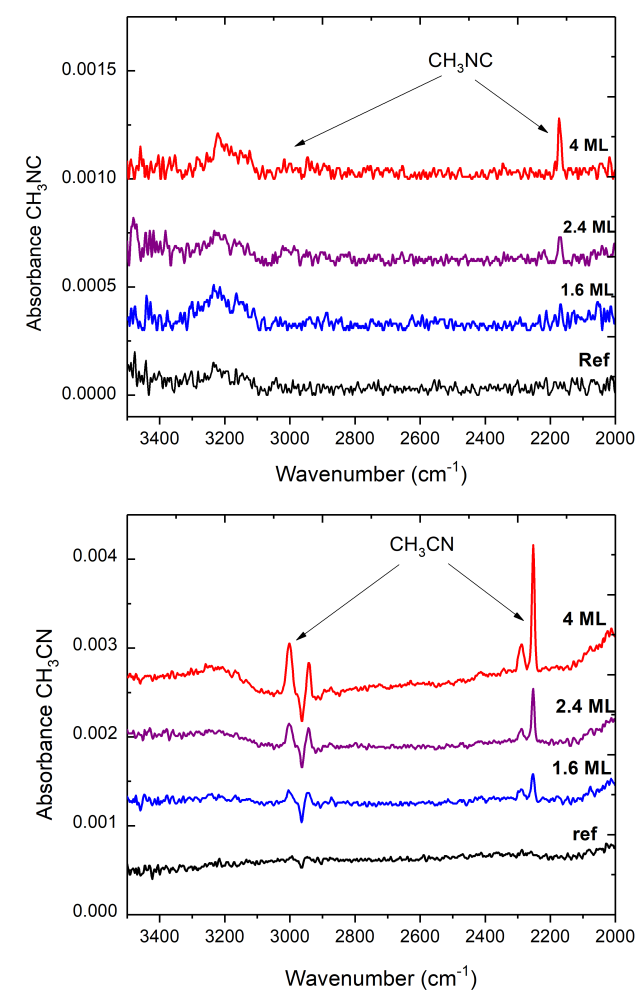

Fig. 1. FT-RAIRS spectra of pure $\mathrm{CH}_{3} \mathrm{NC}$ (top panel) and $\mathrm{CH}_{3} \mathrm{CN}$ (bottom panel) deposited separately at $10 \mathrm{~K}$ for different surface coverages.

Figure 1 shows the FT-RAIRS spectra of $\mathrm{CH}_{3} \mathrm{CN}$ and $\mathrm{CH}_{3} \mathrm{NC}$ obtained for different coverages, expressed in monolayers $\left(1 \mathrm{ML}=10^{15}\right.$ molecules $\left.\mathrm{cm}^{-2}\right)$. In this work the ML unit is to be intended as an exposed dose, namely the amount of deposited species. In fact, in the case of not-wetting molecules the determination of the coverage is difficult, or in the case of radicals like $\mathrm{H}$ atoms the deposited amount either desorbs or reacts. The surface is kept at $10 \mathrm{~K}$. The black curves of Fig. 1 correspond to no exposure, the blue curves to $1.6 \mathrm{ML}$, the purple curves to $2.4 \mathrm{ML}$, and the red curves to $4 \mathrm{ML}$. The determination of $1 \mathrm{ML}$ deposition is accomplished within an accuracy of about $20 \%$. This is carried out by scaling the flux used for different species such as $\mathrm{CO}$, which have good wetting properties and allow us to determine the actual coverage (see Nguyen et al. 2018, for further details). Infrared band strength benchmarking confirms the determination of the adsorbate dose. In Fig. 1 we can clearly observe the difference of the stretching vibrations of cyanide $(-\mathrm{CN})$ group at $2250 \mathrm{~cm}^{-1}$ and isocyanide (-NC) group at $2176 \mathrm{~cm}^{-1}$. Features around $3003 \mathrm{~cm}^{-1}$ for $\mathrm{CH}_{3} \mathrm{CN}$ are more marked than that of $3008 \mathrm{~cm}^{-1}$ for $\mathrm{CH}_{3} \mathrm{NC}$. Infrared spectra are in agreement with those in the literature (Bertin et al. 2017; Murphy et al. 2000).

A TPD analysis completes IR in situ observations. The TPD profiles obtained after the separate deposition of $4 \mathrm{ML}$ of each isomers are shown in Fig. 2. Despite the fact that $\mathrm{CH}_{3} \mathrm{CN}$ and $\mathrm{CH}_{3} \mathrm{NC}$ have the same mass $(\mathrm{m} / \mathrm{z}=41)$, it is possible to identify the isomer by observing their different cracking patterns consisting of mass 40 and 39, respectively. But the most interesting point is that $\mathrm{CH}_{3} \mathrm{NC}$ desorbs earlier (its maximum is at $120 \mathrm{~K}$ for this specific coverage and heating ramp) than $\mathrm{CH}_{3} \mathrm{CN}$, which shows a maximum at $127 \mathrm{~K}$. So it is easy to distinguish the two isomers, thanks to their IR bands or desorption profiles.

For experiments performed in a water ice environment, the water inlet is connected directly to the main chamber and the $\mathrm{H}_{2} \mathrm{O}$ vapor leak is controlled by a throttling valve. The pressure 


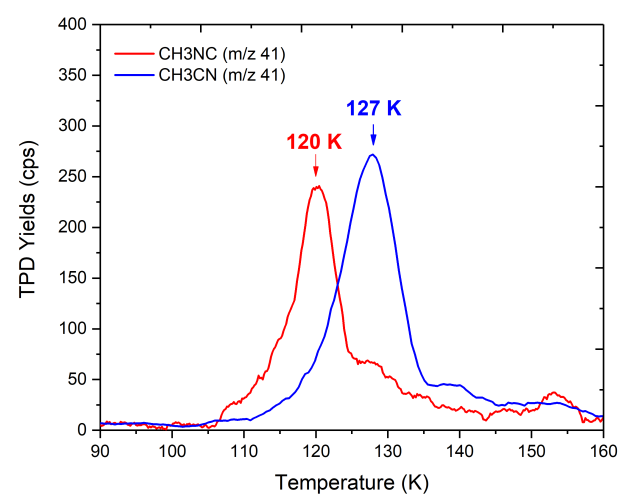

Fig. 2. TPD traces of $\mathrm{CH}_{3} \mathrm{NC}$ (red curve) and $\mathrm{CH}_{3} \mathrm{CN}$ (blue curve) obtained after separate depositions of $6 \mathrm{ML}$ of the species on the gold surface held at $10 \mathrm{~K}$.

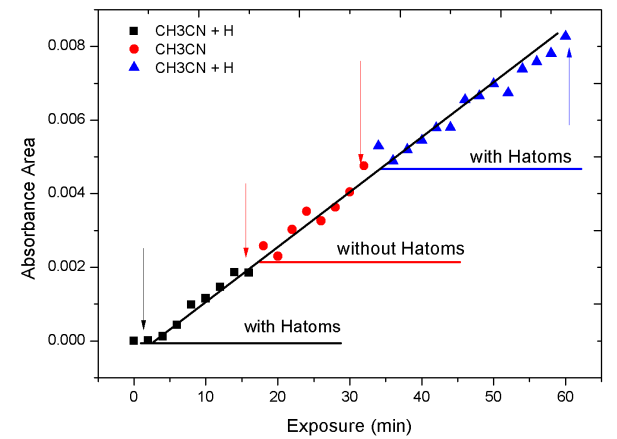

Fig. 3. Evolution of the area of the $2250 \mathrm{~cm}^{-1}$ IR band of $\mathrm{CH}_{3} \mathrm{CN}$ as a function of deposition time on the substrate held at $10 \mathrm{~K}$. H is codeposited during the initial and final phases (black squares and blue triangles) and is absent (red circles) in the second phase.

of the main chamber is few $\times 10^{-8}$ mbar before injecting the reactants and is kept constant. Water deposition is controlled via IR and QMS during all the process. $\mathrm{CH}_{3} \mathrm{NC}, \mathrm{H}$ atoms, and $\mathrm{H}_{2} \mathrm{O}$ are co-deposited on the surface during $30 \mathrm{~min}$, thus $\mathrm{CH}_{3} \mathrm{NC}$ is stopped while $\mathrm{H}$ and $\mathrm{H}_{2} \mathrm{O}$ continue to be deposited for 10 extra minutes. In total 6 monolayers of $\mathrm{CH}_{3} \mathrm{NC}$ and 20 monolayers of $\mathrm{H}$ and $\mathrm{H}_{2} \mathrm{O}$ are deposited. Because the surface is held at $10 \mathrm{~K}$, the water ice network is very porous and does not prevent the access of $\mathrm{H}$ to $\mathrm{CH}_{3} \mathrm{NC}$ efficiently (Minissale et al. 2019). Nonetheless, if we take into account the relative fluxes (water flux is 2.5 higher than the $\mathrm{CH}_{3} \mathrm{NC}$ flux), most of $\mathrm{CH}_{3} \mathrm{NC}$ adsorbate should have at least one $\mathrm{H}_{2} \mathrm{O}$ neighbor.

\subsection{Probing the reaction paths by TPD-QMS analysis}

\subsection{1. (Non)reaction between acetonitrile $\left(\mathrm{CH}_{3} \mathrm{CN}\right)$ and $\mathrm{H}$ atoms at $10 \mathrm{~K}$}

The first experiment consists in monitoring the growth of the $2250 \mathrm{~cm}^{-1}$ IR feature of $\mathrm{CH}_{3} \mathrm{CN}$ with or without $\mathrm{H}$ addition. During the first 16 min $\mathrm{CH}_{3} \mathrm{CN}$ is co-deposited with $\mathrm{H}$ atoms. Area of the IR band is represented as a black dot in Fig. 3. It shows a linear increase. The $\mathrm{H}$ beam thus is turned off and the growth of the IR band is plotted in red. After 40 min the $\mathrm{H}$ beam is switched ON again. Infrared band areas are plotted in blue. Dots can be fitted by a straight line. Independently from the presence of absence of $\mathrm{H}$ atoms, the increase of $\mathrm{CH}_{3} \mathrm{CN}$ molecules is perfectly linear with time. We conclude that in our experimental conditions, $\mathrm{CH}_{3} \mathrm{CN}$ does not efficiently react with $\mathrm{H}$ atoms on a surface held at $10 \mathrm{~K}$.
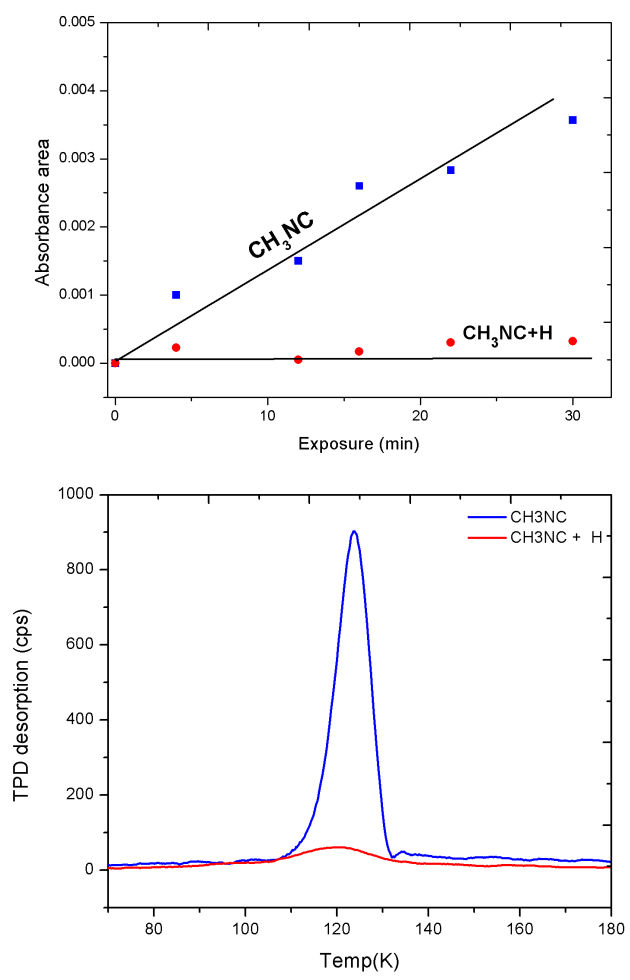

Fig. 4. Top panel: evolution of the area of the $2176 \mathrm{~cm}^{-1} \mathrm{IR}$ band of $\mathrm{CH}_{3} \mathrm{NC}$ as a function of deposition time on the substrate held at $10 \mathrm{~K}$. $\left\{\mathrm{CH}_{3} \mathrm{NC}\right\}$ deposition in blue, and $\left\{\mathrm{CH}_{3} \mathrm{NC}+\mathrm{H}\right\}$ co-deposition in red. Bottom panel: TPD trace $(\mathrm{m} / \mathrm{z}, 41)$ of pure $\left\{\mathrm{CH}_{3} \mathrm{NC}\right\}$ (blue curve) and the remaining part of $\mathrm{CH}_{3} \mathrm{NC}$ (red curve) obtained after the same depositions.

\subsubsection{Reactivity between methyl isocyanide $\mathrm{CH}_{3} \mathrm{NC}$ and $\mathrm{H}$ atoms at $10 \mathrm{~K}$}

Similarly, we can compare depositions of methyl isocyanide $\left(\mathrm{CH}_{3} \mathrm{NC}\right)$ on the golden surface maintained at $10 \mathrm{~K}$ in the presence and absence of $\mathrm{H}$ atoms co-deposition (Fig. 4, top panel). In contrast to the case of acetonitrile $\left(\mathrm{CH}_{3} \mathrm{CN}\right)$, slopes are very different. For the $\left\{\mathrm{CH}_{3} \mathrm{NC}+\mathrm{H}\right\}$ experiment, the IR bands are under the noise level. Including error bars, we obtain a reduction factor of more than $87 \%$ in the amount of consumed $\mathrm{CH}_{3} \mathrm{NC}$. Moreover, the TPD profiles of pure $\mathrm{CH}_{3} \mathrm{NC}$ (blue curve) and remaining $\mathrm{CH}_{3} \mathrm{NC}$ (red curve) are obtained after completing both depositions. These profiles are shown in the bottom panel of Fig. 4. Similarly to areas of FT-RAIRS band, the amount of $\mathrm{CH}_{3} \mathrm{NC}$ molecules desorbing are reduced from 875 to 80 counts. $\mathrm{K}$ corresponding to a reduction factor of $1-\frac{80}{875} \approx 90 \%$. Both FT-RAIRS spectra and TPD profiles provide the same reduction factor for $\mathrm{CH}_{3} \mathrm{NC}$ indicating its high consumption by $\mathrm{H}$ atoms. This demonstrates that the $\mathrm{CH}_{3} \mathrm{NC}$ molecules are reacting efficiently with $\mathrm{H}$ atoms on a $10 \mathrm{~K}$ surface.

It is not possible to isolate in the IR spectra some growth of bands that would have been characteristic of products. But the IR spectra inform us that no matter what the origins of the products are, they are not made from the initial reactants during the TPD because they are all consumed at $10 \mathrm{~K}$. Actually, $\mathrm{CH}_{3} \mathrm{NC}$ remains undetectable and $\mathrm{H}$ is known to be steadily transformed in $\mathrm{H}_{2}$ even on a cold surface (Amiaud et al. 2007; Hama et al. 2012; Wakelam et al. 2017).

Figure 5 shows the TPD traces of products that are formed from the reactions between $\mathrm{CH}_{3} \mathrm{NC}$ and $\mathrm{H}$ atoms. There are three successive desorption zones peaking at 105, 120, and $132 \mathrm{~K}$, indicating at least that different molecules are formed. The first 

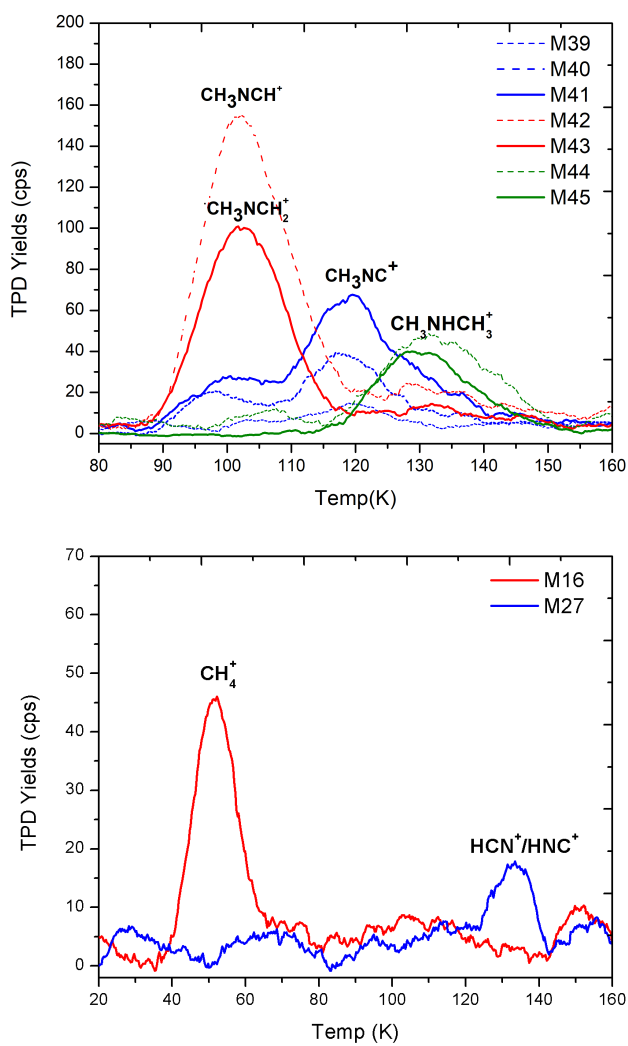

Fig. 5. Top panel: TPD traces of $\mathrm{CH}_{3} \mathrm{NCH}_{2}^{+}(\mathrm{m} / \mathrm{z}, 43$ - solid red curve $)$ and cracking pattern $\mathrm{m} / z 42\left(\mathrm{CH}_{3} \mathrm{NCH}^{+}{ }^{+}\right.$- dashed red curve) desorb around $90-115 \mathrm{~K}$; remaining $\mathrm{CH}_{3} \mathrm{NC}^{+}(\mathrm{m} / z$ 41) (solid blue curve) and cracking pattern $\mathrm{m} / \mathrm{z} 39$ and 40 (dash blue curves) desorb around 110-125 K; finally, dimethylamine $\left(\mathrm{CH}_{3} \mathrm{NHCH}_{3}^{+}\right)(\mathrm{m} / z) 45$ - solid green curve) and cracking patterns $\mathrm{m} / \mathrm{z} 44$ (dash green curve), $\mathrm{m} / \mathrm{z}, 43$ (solid red curve), and $\mathrm{m} / \mathrm{z} 42$ (dash red curve) desorb around $120-145 \mathrm{~K}$. Bottom panel: TPD traces of $\mathrm{CH}_{4}^{+}$(red curve) and $\mathrm{HCN}^{+}$(or $\mathrm{HNC}^{+}$) (blue curve) are formed from other chemical pathways between $\mathrm{CH}_{3} \mathrm{NC}$ and $\mathrm{H}$ atoms.

peak $(87$ to $117 \mathrm{~K})$ is dominated by the mass $42\left(\mathrm{CH}_{3} \mathrm{NCH}^{+}-\right.$ dashed red curve), which corresponds to one extra $\mathrm{H}$ to $\mathrm{CH}_{3} \mathrm{NC}$ and mass 43 (solid red curve), which corresponds to the addition of $2 \mathrm{H}$ atoms. Because of the perfect similarity of the temperature profiles, both peaks come from the same mother molecule, which should be $\mathrm{CH}_{3} \mathrm{NCH}_{2}$. In mass spectroscopy, methyl groups $-\mathrm{CH}_{3}$ are often ionized in $-\mathrm{CH}_{2}^{+}$because $-\mathrm{CH}_{3}^{+}$ is a radical and so is less energetically favorable. As examples, the major products of the $70 \mathrm{eV}$ electron impact of methylamine $\mathrm{CH}_{3} \mathrm{NH}_{2}(m / z=31)$ and methanol $\mathrm{CH}_{3} \mathrm{OH}(m / z=32)$, are $m / z=30$ and $m / z=31$, respectively (Nist webbook).

The second peak around $120 \mathrm{~K}$ is a small signal of $\mathrm{CH}_{3} \mathrm{NC}$ (solid blue curve). It is the same peak shown in Fig. 4, but the vertical scale is very different. The peak is slightly shifted toward higher temperatures. It could be the signature of some isomerization because $\mathrm{CH}_{3} \mathrm{CN}$ is desorbing at higher temperature than $\mathrm{CH}_{3} \mathrm{NC}$. However, the molecular environment has also changed because of the presence of others products. As a result, the binding energy and thus the desorption profiles can be affected. As a consequence, we cannot firmly conclude that there is isomerization, but we cannot exclude it.

The last peak from 120 to $150 \mathrm{~K}$ is dominated by masses $44\left(\mathrm{CH}_{3} \mathrm{NHCH}_{2}^{+}\right.$- dashed green curve $)$and $45\left(\mathrm{CH}_{3} \mathrm{NHCH}_{3}^{+}-\right.$ solid green curve), which correspond to the reported cracking patterns of dimethyl amine $\mathrm{CH}_{3} \mathrm{NHCH}_{3}$, and thus the addition of $4 \mathrm{H}$ atoms.
The bottom panel shows the mass 16 (main peak of methane $\mathrm{CH}_{4}$ - solid red curve). Its desorption temperature $(40-60 \mathrm{~K})$ is typical and very different from other molecules, so there is no doubt about the methane production. If $\mathrm{CH}_{3} \mathrm{NC}$ is fragmented during hydrogenation, some correlation with $\mathrm{CH}_{4}$ and $\mathrm{HCN}$ or HNC should be found. The corresponding mass $(\mathrm{m} / \mathrm{z}=27)$ is also shown in blue in the bottom panel of Fig. 5. The temperature of desorption around $130 \mathrm{~K}$ could indicate that it is a cracking pattern of dimethylamine, but it is reported in databases and in Table A.1 that this fragment is only few $\%$ of the major ion, so it is not measurable out of the noise in our experimental conditions. The temperature of desorption corresponds to sublimation of HCN (Theule et al. 2011). Therefore there is no doubt that some fragmentation occurs during the hydrogenation of $\mathrm{CH}_{3} \mathrm{NC}$.

We can sum up the $\left\{\mathrm{CH}_{3} \mathrm{CN} / \mathrm{CH}_{3} \mathrm{NC}+\mathrm{H}\right\}$ first experimental results through the following statements:

(i) $\mathrm{CH}_{3} \mathrm{CN}$ does not react with $\mathrm{H}$ atoms at low temperatures.

(ii) $\mathrm{CH}_{3} \mathrm{NC}$ reacts with $\mathrm{H}$ atoms forming: $\mathrm{CH}_{3} \mathrm{NCH}_{2}$, $\mathrm{CH}_{3} \mathrm{NHCH}_{3}, \mathrm{CH}_{4}, \mathrm{HCN}$, and possibly $\mathrm{CH}_{3} \mathrm{CN}$.

(iii) We can explain the presence of these products through the following reaction paths:

$$
\begin{aligned}
& \mathrm{CH}_{3} \mathrm{NC} \stackrel{+2 \mathrm{H}}{\longrightarrow} \mathrm{CH}_{3} \mathrm{NCH}_{2} \stackrel{+2 \mathrm{H}}{\longrightarrow} \mathrm{CH}_{3} \mathrm{NHCH}_{3}, \\
& \mathrm{CH}_{3} \mathrm{NC}+2 \mathrm{H} \rightarrow \mathrm{CH}_{4}+\mathrm{HCN} / \mathrm{HNC}, \\
& \mathrm{CH}_{3} \mathrm{NC} \stackrel{?}{\rightarrow} \mathrm{CH}_{3} \mathrm{CN} .
\end{aligned}
$$

\subsection{3. $\mathrm{CH}_{3} \mathrm{NC}$ and its hydrogenation in the presence of $\mathrm{H}_{2} \mathrm{O}$}

Desorption of $\mathrm{CH}_{3} \mathrm{NC}$ mixed with $\mathrm{H}_{2} \mathrm{O}$. Before performing hydrogenation experiments, it is important to determine if the water and $\mathrm{CH}_{3} \mathrm{NC}$ react together. Indeed, some stable molecules (such as $\mathrm{NH}_{3}, \mathrm{CO}_{2}, \mathrm{H}_{2} \mathrm{CO}, \mathrm{H}_{2} \mathrm{O}_{2}$ ) are known to undergo activated thermal reactions that may be modified by the presence of water (Theulé et al. 2013; Duvernay et al. 2014; Dulieu et al. 2017).

We applied the protocol described in the experimental section. $\mathrm{CH}_{3} \mathrm{NC}$ is injected using the central beam, whereas $\mathrm{H}_{2} \mathrm{O}$ is grown by background deposition while the surface is maintained at $10 \mathrm{~K}$. The doses correspond to $6 \mathrm{MLs}$ for $\mathrm{CH}_{3} \mathrm{NC}$ and $20 \mathrm{MLs}$ for $\mathrm{H}_{2} \mathrm{O}$. However, since the surface deposition of the beam is a diameter of about $3 \mathrm{~mm}$ and the total diameter of the gold sample is $9 \mathrm{~mm}$, the water signal is much more intense. Most of the surface of the sample is only covered with water. Still, $\mathrm{CH}_{3} \mathrm{NC}$ is perfectly and homogeneously overlapped by $\mathrm{H}_{2} \mathrm{O}$ with a ratio of $10 \mathrm{H}_{2} \mathrm{O}$ for $3 \mathrm{CH}_{3} \mathrm{NC}$ molecules in the mixing area.

The TPD profiles of the $\left\{\mathrm{CH}_{3} \mathrm{NC}\right\}$ and $\left\{\mathrm{CH}_{3} \mathrm{NC}+\mathrm{H}_{2} \mathrm{O}\right\}$ systems are shown in Fig. 6. In the absence of $\mathrm{H}_{2} \mathrm{O}, \mathrm{CH}_{3} \mathrm{NC}$ (blue curve) desorption is finished at a lower temperature than the desorption of water (measurable in our experimental conditions above $130 \mathrm{~K}$ ), meanwhile the $\mathrm{CH}_{3} \mathrm{NC}$ desorption (red curve) is split in two parts when co-deposited with $\mathrm{H}_{2} \mathrm{O}$. A fraction desorbs before $\mathrm{H}_{2} \mathrm{O}$ and the other part is co-desorbing with $\mathrm{H}_{2} \mathrm{O}$. More precisely, $\mathrm{CH}_{3} \mathrm{NC}$ mostly desorbs during the amorphous desorption phase (Speedy et al. 1996), which occurs before the change in the slope of desorption of water at around $140 \mathrm{~K}$. A smallest and last fraction of $\mathrm{CH}_{3} \mathrm{NC}$ is desorbing just after the crystallization. We do not observe an obvious volcano effect, nor desorption after the water, as can be seen for others species and/or substrates (Collings et al. 2004; Chaabouni et al. 2018). It means that a part of $\mathrm{CH}_{3} \mathrm{NC}$ is trapped inside $\mathrm{H}_{2} \mathrm{O}$ and then it desorbs when released from $\mathrm{H}_{2} \mathrm{O}$. We calculated the desorption areas of pure $\left\{\mathrm{CH}_{3} \mathrm{NC}\right\}$ and $\left\{\mathrm{CH}_{3} \mathrm{NC}+\mathrm{H}_{2} \mathrm{O}\right\}$ 
Table 1. Percentages (\%) of the remnants $\left(\mathrm{CH}_{3} \mathrm{NC}\right)$ and products after the deposition of pure $\mathrm{CH}_{3} \mathrm{NC}_{2}\left\{\mathrm{CH}_{3} \mathrm{NC}+\mathrm{H}_{2} \mathrm{O}\right\},\left\{\mathrm{CH}_{3} \mathrm{NC}+\mathrm{H}\right\}$, and $\left\{\mathrm{CH}_{3} \mathrm{NC}+\mathrm{H}+\mathrm{H}_{2} \mathrm{O}\right\}$ co-depositions on surface held at $10 \mathrm{~K}$.

\begin{tabular}{ccccccc}
\hline \hline Experiment & $\begin{array}{c}M_{\mathrm{CH}_{3} \mathrm{NC}} \\
(\%)\end{array}$ & $\begin{array}{c}M_{\mathrm{CH}_{3} \mathrm{NC}}+2 \mathrm{H} \\
(\%)\end{array}$ & $\begin{array}{c}M_{\mathrm{CH}_{3} \mathrm{NC}}+4 \mathrm{H} \\
(\%)\end{array}$ & $\begin{array}{c}\text { Fragmentation } \\
(\%)\end{array}$ & $\begin{array}{c}\text { Isomerization } \\
(\%)\end{array}$ & $\begin{array}{c}\text { Total } \\
(\%)\end{array}$ \\
\hline $\mathrm{CH}_{3} \mathrm{NC}$ & 100 & 0 & 0 & 0 & 0 & 100 \\
$\mathrm{CH}_{3} \mathrm{NC}+\mathrm{H}_{2} \mathrm{O}$ & 100 & 0 & 0 & 0 & 0 & 100 \\
$\mathrm{CH}_{3} \mathrm{NC}+\mathrm{H}$ & 15 & 34 & 16 & 7 & 2 & 74 \\
$\mathrm{CH}_{3} \mathrm{NC}+\mathrm{H}+\mathrm{H}_{2} \mathrm{O}$ & 12 & 21 & 35 & 8 & Unknown & 76 \\
\hline
\end{tabular}

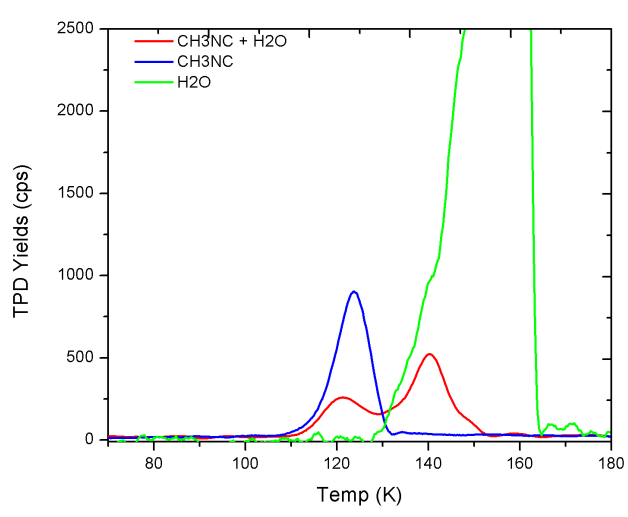

Fig. 6. Desorption profiles of pure $\mathrm{CH}_{3} \mathrm{NC}$ (blue curve) and $\left\{\mathrm{CH}_{3} \mathrm{NC}+\right.$ $\mathrm{H}_{2} \mathrm{O}$ \} (red and green curves).

and the ratio gives a factor of 1 . This means that $\mathrm{CH}_{3} \mathrm{NC}$ does not react with $\mathrm{H}_{2} \mathrm{O}$, although $\mathrm{CH}_{3} \mathrm{NC}$ is trapped inside $\mathrm{H}_{2} \mathrm{O}$. No indication of reactivity can be addressed for this system.

To sum up the experimental results of the interaction between $\mathrm{CH}_{3} \mathrm{NC}$ and $\mathrm{H}_{2} \mathrm{O}$, we give the statements:

(iv) $\mathrm{CH}_{3} \mathrm{NC}$ does not react with $\mathrm{H}_{2} \mathrm{O}$.

(v) $\mathrm{CH}_{3} \mathrm{NC}$ is trapped and released with $\mathrm{H}_{2} \mathrm{O}$.

Reaction of $\mathrm{CH}_{3} \mathrm{NC}$ and $\mathrm{H}$ atoms in the presence of $\mathrm{H}_{2} \mathrm{O}$. For this experiment both $\mathrm{H}$ (via the right beam) and $\mathrm{H}_{2} \mathrm{O}$ (via background deposition) are deposited during $40 \mathrm{~min}$, while $\mathrm{CH}_{3} \mathrm{NC}$ is only injected for $30 \mathrm{~min}$. The doses are $6 \mathrm{ML}$ for $\mathrm{CH}_{3} \mathrm{NC}$ and $20 \mathrm{ML}$ for $\mathrm{H}$ and $\mathrm{H}_{2} \mathrm{O}$.

Figure 7 shows the TPD profiles obtained after the reactions between $\mathrm{CH}_{3} \mathrm{NC}$ and $\mathrm{H}$ atoms in the presence of $\mathrm{H}_{2} \mathrm{O}$. Remnants and products present broad and less featured desorption profiles. This is due to the necessity to diffuse out of the water ice. The dynamic of the desorption of mixed ice is not the purpose of this article. The key observation is that the ratio in the products have changed. Especially, $\mathrm{CH}_{3} \mathrm{NHCH}_{3}$ (solid green curve) is clearly enhanced, dominating all the other products or remnants. We propose in Eq. (2) that the hydrogenation occurs in two main steps, first $\mathrm{CH}_{3} \mathrm{NCH}_{2}$ and second $\mathrm{CH}_{3} \mathrm{NHCH}_{3}$. It is clear that in absence of water the hydrogenation is less complete, $\mathrm{CH}_{3} \mathrm{NCH}_{2}$ being the major product at the end, whereas in the presence of water the second step is easier and complete hydrogenation is more often reached. The fragmentation is still occurring.

The quantitative amounts of the different products or remnants are listed in Table 1 . These amounts are obtained by calculating the area under the TPD profiles (including cracking patterns as shown in Table A.1). They are normalized to the amount of $\mathrm{CH}_{3} \mathrm{NC}$ injected in the first experiment. First of all, we stress that the efficiency of QMS detection is not exactly identical from one molecule to another. It can vary by a few tens of

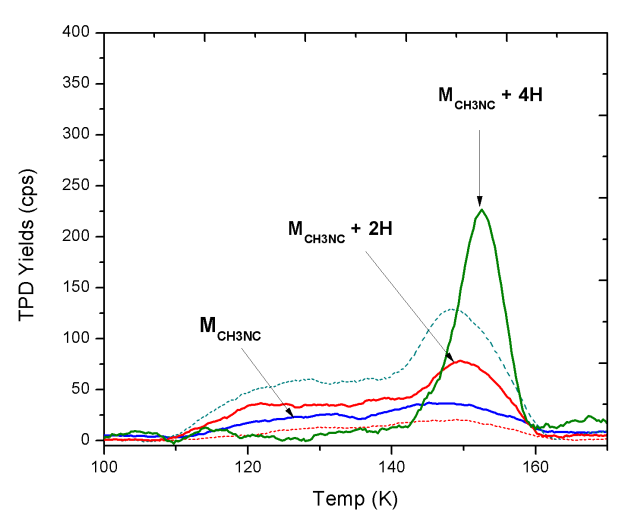

Fig. 7. TPD profiles of the reactivity between $\mathrm{CH}_{3} \mathrm{NC}$ and $\mathrm{H}$ atoms in the presence of $\mathrm{H}_{2} \mathrm{O} . \mathrm{CH}_{3} \mathrm{NHCH}_{3}\left(M_{\mathrm{CH} 3 \mathrm{NC}}+4 \mathrm{H}\right)$ (solid green curve) is enhanced after completing the deposition. A part of $\mathrm{CH}_{3} \mathrm{NC}\left(M_{\mathrm{CH} 3 \mathrm{NC}}-\right.$ solid blue curve $)$ and $\mathrm{CH}_{3} \mathrm{NCH}_{2}\left(M_{\mathrm{CH} 3 \mathrm{NC}}+2 \mathrm{H}\right.$ - solid red curve) desorb before $\mathrm{H}_{2} \mathrm{O}$ and the other part is trapped and desorbed with $\mathrm{H}_{2} \mathrm{O}$.

percent for these molecules. It is due to the different ionization cross sections (which can be calculated), but also to the different spatial and kinetic distributions of the different species that desorb (unknown). Even though cracking patterns are included in the estimation, the ratios presented in the table do not exactly represent the species ratio but rather give a good indication. In the same column, the relative error is similar, so if we underestimate or overestimate one species, we do the same way for all the experiments. Therefore, it is possible that the total, which is less than $100 \%$ in case of reactivity experiments, does not represent a real lost of reactants, but more the inaccuracy of the method. However, it could also be due to losses investigated by the chemical desorption process (Dulieu et al. 2013). This aspect is discussed later. No matter what the source of uncertainties are, the table makes clear that the hydrogenation in presence of water is more efficient. There are fewer remaining products $(12 \%$ instead of $15 \%$ ) and the first measurable step of hydrogenation $\left(\mathrm{CH}_{3} \mathrm{NCH}_{2}\right)$ is largely transferred in the second, $\mathrm{CH}_{3} \mathrm{NHCH}_{3}$. We can give the following statement from the experiment of $\mathrm{CH}_{3} \mathrm{NC}$ and $\mathrm{H}$ atoms in the presence of $\mathrm{H}_{2} \mathrm{O}$ :

(vi) $\mathrm{H}_{2} \mathrm{O}$ has a catalytic role for the hydrogenation of $\mathrm{CH}_{3} \mathrm{NC}$.

\subsubsection{Reactivity of $\mathrm{CH}_{3} \mathrm{NC}$ and $\mathrm{D}$ atoms on the golden surface at $10 \mathrm{~K}$}

We performed deuteration of $\mathrm{CH}_{3} \mathrm{NC}$ with $\mathrm{D}$ atoms in the same conditions (i.e., surface temperature and molecular dosage). $\mathrm{CH}_{3} \mathrm{NC}$ and $\mathrm{D}$ atoms co-deposited during $30 \mathrm{~min}$ and an additional $10 \mathrm{~min}$ of $\mathrm{D}$ atoms exposure is applied. In contrast with $\mathrm{H}$ experiments, only $\sim 44 \% \pm 6 \%$ of $\mathrm{CH}_{3} \mathrm{NC}$ is consumed by $\mathrm{D}$ atoms. Figure 8 shows the comparison between pure $\mathrm{CH}_{3} \mathrm{NC}$ (blue curve) and the remaining $\mathrm{CH}_{3} \mathrm{NC}$ (red curve) after 
Table 2. Percentages (\%) of remnants $\left(\mathrm{CH}_{3} \mathrm{NC}\right)$ and products after completing the co-deposition of $\mathrm{CH}_{3} \mathrm{NC}$ and $\mathrm{H} / \mathrm{D}$ atoms at $10 \mathrm{~K}$.

\begin{tabular}{ccccccc}
\hline \hline Experiment & $\begin{array}{c}M_{\mathrm{CH}_{3} \mathrm{NC}} \\
(\%)\end{array}$ & $\begin{array}{c}M_{\mathrm{CH}_{3} \mathrm{NC}}+2 \mathrm{H}(2 \mathrm{D}) \\
(\%)\end{array}$ & $\begin{array}{c}M_{\mathrm{CH}_{3} \mathrm{NC}}+4 \mathrm{H}(4 \mathrm{D}) \\
(\%)\end{array}$ & $\begin{array}{c}\text { Fragmentation } \\
(\%)\end{array}$ & $\begin{array}{c}\text { Isomerization } \\
(\%)\end{array}$ & $\begin{array}{c}\text { Total } \\
(\%)\end{array}$ \\
\hline $\mathrm{CH}_{3} \mathrm{NC}$ & 100 & 0 & 0 & 0 & 0 & 100 \\
$\mathrm{CH}_{3} \mathrm{NC}+\mathrm{H}$ & 15 & 34 & 16 & 7 & 2 & 74 \\
$\mathrm{CH}_{3} \mathrm{NC}+\mathrm{D}$ & 56 & 9 & 0 & 4 & 0 & 69 \\
\hline
\end{tabular}
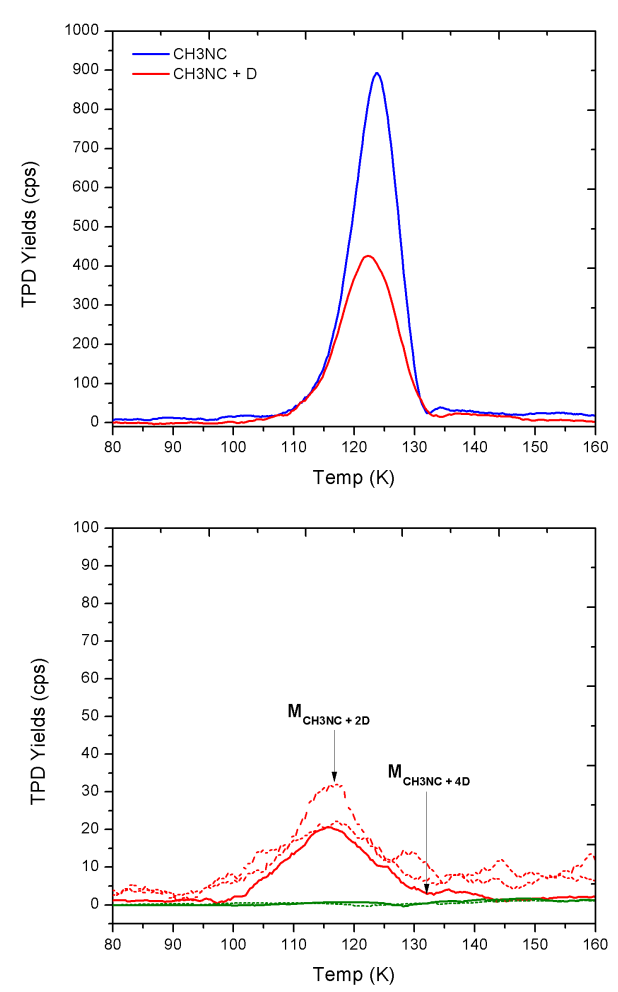

Fig. 8. Top panel: pure $\mathrm{CH}_{3} \mathrm{NC}(\mathrm{m} / \mathrm{z}, 41$ - blue curve) and remaining $\mathrm{CH}_{3} \mathrm{NC}(\mathrm{m} / \mathrm{z} 41-$ red curve $)$ after completing the reaction with $\mathrm{D}$ atoms at $10 \mathrm{~K}$. Bottom panel: TPD traces of mass $45\left(\mathrm{M}_{\mathrm{CH}_{3} \mathrm{NC}}+2 \mathrm{D}\right.$-solid red curve) and cracking pattern $(\mathrm{m} / \mathrm{z}, 43$, and 44$)$ (dashed red curves) corresponding to $\mathrm{CH}_{3} \mathrm{NCD}_{2}$. No traces of $\mathrm{CH}_{3} \mathrm{NDCD}_{3}$ are detected $\left(\mathrm{M}_{\mathrm{CH}_{3} \mathrm{NC}}+4 \mathrm{D}\right.$-solid green curve $)$.

completing the reaction (top panel). Thus, $\mathrm{CH}_{3} \mathrm{NC}$ is less reactive with $\mathrm{D}$ at low temperature and the first step of the reaction is not complete.

The bottom panel of Fig. 8 shows the products obtained after deuteration of $\mathrm{CH}_{3} \mathrm{NC}$. The first step of the deuteration can be seen through the parent mass 45 corresponding to $\mathrm{CH}_{3} \mathrm{NCD}_{2}$ and is desorbing around $115 \mathrm{~K}$. Cracking patterns of $\mathrm{m} / \mathrm{z} 43$ and 44 are also present and are of about the same intensity. On the contrary the trace for $m / z 46$ and 47 corresponding to dimethylamine $\left(\mathrm{CH}_{3} \mathrm{NDCD}_{3}\right)$ and its fragmentations are undetectable. Moreover, the fragmentation pathway is observed and some $\mathrm{CH}_{3} \mathrm{D}(\mathrm{m} / \mathrm{z}, 17)$ and $\mathrm{DCN}(\mathrm{m} / \mathrm{z} 28)$ are detected. The quantitative analysis is listed in Table 2.

We can describe the chemical network of $\left\{\mathrm{CH}_{3} \mathrm{NC}+\mathrm{D}\right\}$ atoms with the reactions

$$
\begin{aligned}
& \mathrm{CH}_{3} \mathrm{NC}+2 \mathrm{D} \rightarrow \mathrm{CH}_{3} \mathrm{NCD}_{2}, \\
& \mathrm{CH}_{3} \mathrm{NC}+2 \mathrm{D} \rightarrow \mathrm{CH}_{3} \mathrm{D}+\mathrm{DCN} / \mathrm{DNC} .
\end{aligned}
$$

From the present set of the $\left\{\mathrm{CH}_{3} \mathrm{NC}+\mathrm{D}\right\}$ experiment, we summarize our findings as follows: (vii) deuteration of $\mathrm{CH}_{3} \mathrm{NC}$ is uncompleted at low temperatures, and

(viii) $\mathrm{D}$ atoms have an entrance activation barrier.

\subsubsection{Reactivity of $\mathrm{CH}_{3} \mathrm{NC}$ and $\mathrm{H}$ atoms at various temperatures.}

We have seen earlier that $\mathrm{CH}_{3} \mathrm{NC}$ can be almost fully consumed by $\mathrm{H}$ atoms at $10 \mathrm{~K}$ whereas this is not the case with $\mathrm{D}$ atoms, suggesting that the $\mathrm{CH}_{3} \mathrm{NC}+\mathrm{D}$ reaction has an entrance barrier and is slower than the $\mathrm{CH}_{3} \mathrm{NC}+\mathrm{H}$ reaction. Surface reactivity is actually a kinetic competition between many different reactive pathways, the most important in the case of hydrogenation being the self reaction $\mathrm{H}+\mathrm{H} \longrightarrow \mathrm{H}_{2}$. Thus by changing the surface temperature, we can change the kinetics and see how the products are affected.

The top panel of Fig. 9 shows the remaining $\mathrm{CH}_{3} \mathrm{NC}$ at different surface temperatures after completing the same $\left\{\mathrm{CH}_{3} \mathrm{NC}+\mathrm{H}\right\}$ co-depositions. The remaining $\mathrm{CH}_{3} \mathrm{NC}$ increases with the surface temperature. The products are shown in the middle and bottom panels. The $\mathrm{CH}_{3} \mathrm{NCH}_{2}$ yield decreases when the surface temperature increases, which is also the case for $\mathrm{CH}_{3} \mathrm{NHCH}_{3}$ which becomes undetectable above $20 \mathrm{~K}$ on TPD profiles. Table 3 lists the quantitative values.

We point out that the consumption of reactants is different at 30 and $40 \mathrm{~K}$ (respectively 58 and $48 \%$, respectively), whereas the product yield is about the same ( 9 and $8 \%$ ).

We can give the following statement for these experimental results:

(ix) At higher temperatures, the reaction between $\mathrm{CH}_{3} \mathrm{NC}$ and $\mathrm{H}$ atoms is reduced because of the activation barriers.

\section{Theoretical approach to hydrogenation processes}

\subsection{Strategy and computational methods}

In view of the number of calculations to be performed in this work and of the complementary work to come on similar subjects we found it necessary to reach a compromise between level of theory and computational effort. We took the first two steps of reaction paths a and $\mathrm{b}$ for case studies, namely

$$
\mathrm{CH}_{3} \mathrm{CN}+\mathrm{H}^{\bullet} \rightarrow \mathrm{CH}_{3} \mathrm{CHN}^{\bullet 3}
$$

and

$$
\mathrm{CH}_{3} \mathrm{NC}+\mathrm{H}^{\bullet} \rightarrow \mathrm{CH}_{3} \mathrm{NCH}^{\bullet},
$$

and carried out benchmark studies.

First, calculations at the coupled-cluster single and double excitation (CCSD) level (Purvis \& Bartlett 1982) and at the CCSD level augmented with a noniterative triple excitation

\footnotetext{
3 More stable than $\mathrm{CH}_{3} \mathrm{C}^{\bullet} \mathrm{NH}$

4 More stable than $\mathrm{CH}_{3} \mathrm{NHC}^{\bullet}$.
} 

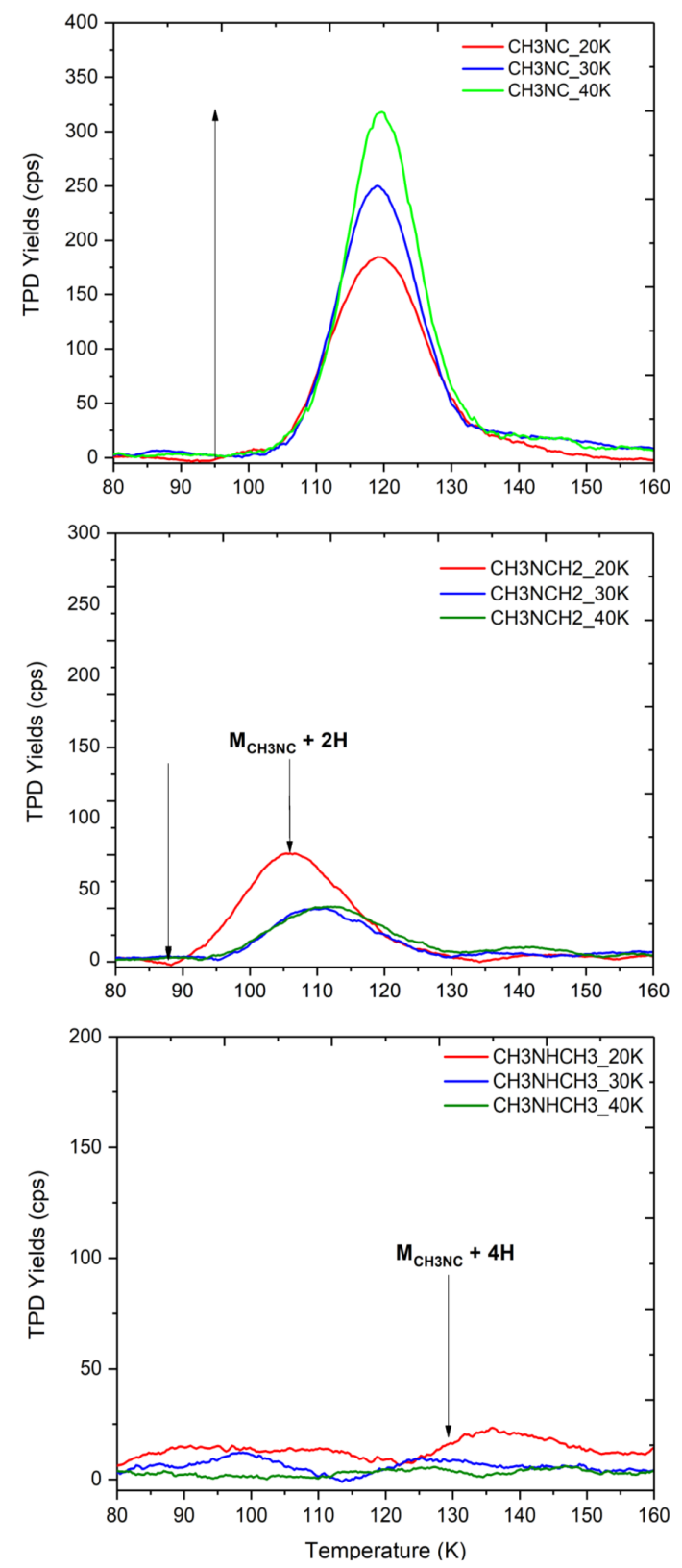

Fig. 9. Top panel: remaining $\mathrm{CH}_{3} \mathrm{NC}$ (from red to green curves) after completing the reaction with $\mathrm{H}$ atoms on the surface with the temperature ranging from 20 to $40 \mathrm{~K}$. Middle panel: TPD traces of $\mathrm{CH}_{3} \mathrm{NCH}_{2}$ $\left(M_{\mathrm{CH}_{3} \mathrm{NC}}+2 \mathrm{H}\right)$ (from red to green curves) are gradually reduced with the surface temperature. Bottom panel: the trace of dimethylamine $\left(\mathrm{CH}_{3} \mathrm{NHCH}_{3}-M_{\mathrm{CH}_{3} \mathrm{NC}}+4 \mathrm{H}\right)$ is not detectable at high temperatures.

correction (CCSD(T)) (Raghavachari et al. 1989) allowed us to establish reference data.

Second, several methods based on the density functional theory (DFT) were then confronted to CCSD and CCSD(T) treatments to determine which level of theory had to be employed for the whole study. We started with the B3LYP functional (Becke 1993; Lee et al. 1988) originally adjusted to reproduce molecular geometries of a panel of representative organic species. Then we tested six functionals developed more recently to account better for weak and long range interactions, belonging to three different families: two meta-GGA functionals, MPWB1K (Zhao \& Truhlar 2004) and M06-2X (Zhao \& Truhlar 2008); two double-hybride functionals, B2PLYP (Grimme 2006) and B2PLYP-D3 (Grimme et al. 2011); and two long-range corrected functionals, LC- $\omega$ PBE (Vydrov \& Scuseria 2006), and $\omega$ B97XD (Chai \& Head-Gordon 2008). These functionals all include a percentage of exact Hartree-Fock (HF) exchange, known to be required for radical systems.

More precisely, the stationary points (reactants, products, and transition states) along paths a and $b$ were first located at the CCSD level. Geometry optimizations were also performed at the Møller-Plesset (MP2) level (Møller \& Plesset 1934), which is often used as a standard in molecular calculations. In this case, energies were refined by single point calculations at the $\operatorname{CCSD}(\mathrm{T})$ level. Geometry optimizations were then repeated at the DFT level. At each level of theory (MP2, CCSD, or DFT), the geometries of the stationary points were fully optimized and verified to be true minima for reactants or first order saddle points for transition states, which allowed us to determine the zero-point vibrational energy correction (ZPE). Moreover, at the temperature of the ISM, entropic contributions to the Gibbs free energies can be neglected so we provide only reaction or activation enthalpies, which reduce to energetic quantities at $0 \mathrm{~K}$. Anticipating a possible situation in case the co-deposition of $\mathrm{H}_{2}$ and nitrile might modify the environment compared with isolated species, the embedded molecules (in ice) were calculated using the polarizable continuum model (PCM), in which the environment is described as a homogeneous medium characterized by an $\epsilon$ dielectric constant (Tomasi \& Persico 1994). The value used is 600 , which is very different from that at room temperature; this value was extrapolated to the $(10-50 \mathrm{~K})$ range characteristic of the ISM from the results obtained in a study of $\epsilon$ at decreasing temperature of water ice (Johari \& Jones 1976). All these calculations were done in conjunction with the aug-cc-pVTZ basis set (Dunning 1989), as implemented in the Gaussian package (Frisch et al. 2009).

\subsection{Benchmarking the DFT approaches}

Taking the CCSD level of calculation as our reference, we found that MP2 leads to an overestimated value of the activation barrier (by a factor of almost 3 for $\mathrm{CH}_{3} \mathrm{CN}$ ) and an underestimation of the exothermicity (by a factor of almost 5 for $\mathrm{CH}_{3} \mathrm{CN}$ ). It is noteworthy that errors are larger for the nitrile than for the isonitrile (Table 4). The perturbative treatment of correlation at MP2, including only doubly excited configurations on top of HF, does not seem to be able to account properly for the interaction with the incoming $\mathrm{H}^{\bullet}$ atom. However, applying $\operatorname{CCSD}(\mathrm{T})$ on top of optimized MP2 geometries helps rectify the energy profile. It should be noted that the CCSD geometries of the transition states are significantly different from those of the MP2 transition states, where the $\mathrm{C}-\mathrm{H}$ distances are underestimated by about $0.15 \AA$.

Contrary to post HF treatments, using DFT provides wellgrouped energies of within $\sim 3.5 \mathrm{kcal} \mathrm{mol}^{-1}$ for $\Delta H^{\ddagger}$ and within $\sim 5 \mathrm{kcal} \mathrm{mol}^{-1}$ for $\Delta H$. The standard B3LYP with only $\sim 20 \%$ of HF exchange appears as an exception. It gives the lowest activation barrier, that is $\sim 2.5 \mathrm{kcal} \mathrm{mol}^{-1}$ below the average of the other functionals, and the highest exothermicity, that is $\sim 3.0 \mathrm{kcal} \mathrm{mol}^{-1}$ above the average of the other functionals. The other six functionals with HF exchange contributions in the range $\sim 40-50 \%$ provide energy values close to those obtained at the CCSD level. The origin of this behavior lies in the fact that introducing the HF exchange in the exchange-correlation functional corrects the known over-delocalization of the electron density at the DFT level.

In view of the aforementioned results we focused on how embedding in the ice may affect the hydrogenation process by 
Table 3. Percentages $(\%)$ of the remnants $\left(\mathrm{CH}_{3} \mathrm{NC}\right)$ and products after completing the depositions at different surface temperatures.

\begin{tabular}{ccccccc}
\hline \hline $\begin{array}{c}\text { Temperature } \\
(\mathrm{K})\end{array}$ & $\begin{array}{c}M_{\mathrm{CH}_{3} \mathrm{NC}} \\
(\%)\end{array}$ & $\begin{array}{c}M_{\mathrm{CH}_{3} \mathrm{NC}}+2 \mathrm{H} \\
(\%)\end{array}$ & $\begin{array}{c}M_{\mathrm{CH}_{3} \mathrm{NC}}+4 \mathrm{H} \\
(\%)\end{array}$ & $\begin{array}{c}\text { Fragmentation } \\
(\%)\end{array}$ & $\begin{array}{c}\text { Isomerization } \\
(\%)\end{array}$ & $\begin{array}{c}\text { Total } \\
(\%)\end{array}$ \\
\hline 10 & 15 & 34 & 16 & 7 & 2 & 74 \\
20 & 37 & 20 & 7 & 6 & 3 & 73 \\
30 & 42 & 9 & 0.3 & 4 & 3 & 58.3 \\
40 & 52 & 8 & 0.0 & 1.4 & 0 & 61.4 \\
\hline
\end{tabular}

Table 4. Reaction $(\Delta H)$ and activation $\left(\Delta H^{\ddagger}\right)$ enthalpies, corrected for $\mathrm{ZPE}$, of the hydrogen addition reaction to $\mathrm{CH}_{3} \mathrm{CN}$ and $\mathrm{CH}_{3} \mathrm{NC}$, calculated at $0 \mathrm{~K}$ with different post-HF and DFT methods $\left(\mathrm{kcal} \mathrm{mol}^{-1}\right)$, in conjunction with the aug-cc-pVTZ basis set.

\begin{tabular}{|c|c|c|c|c|c|}
\hline \multirow{2}{*}{$\begin{array}{l}\text { Level } \\
\text { of theory }\end{array}$} & \multirow{2}{*}{$\begin{array}{l}\% \mathrm{HF} \\
\text { exch. }\end{array}$} & \multicolumn{2}{|c|}{$\mathrm{CH}_{3} \mathrm{CN} \rightarrow \mathrm{CH}_{3} \mathrm{CHN}$} & \multicolumn{2}{|c|}{$\mathrm{CH}_{3} \mathrm{NC} \rightarrow \mathrm{CH}_{3} \mathrm{NCH}$} \\
\hline & & $\Delta H^{\ddagger}$ & $\Delta H$ & $\Delta H^{\ddagger}$ & $\Delta H^{(a)}$ \\
\hline MP2 & & 21.8 & -4.7 & 5.4 & $-15.8(-20.8)$ \\
\hline $\operatorname{CCSD}(\mathrm{T})^{(b)}$ & & 9.2 & -18.7 & 2.2 & $-21.3(-25.9)$ \\
\hline CCSD & & 7.9 & -22.5 & 2.9 & $-23.7(-28.2)$ \\
\hline B3LYP & 20 & 5.2 & -24.6 & 0.2 & $-28.1(-32.3)$ \\
\hline MPWB1K & 44 & 7.6 & -22.1 & 2.2 & $-25.2(-29.5)$ \\
\hline M06-2X & 54 & 7.9 & -20.2 & 2.9 & $-22.6(-26.8)$ \\
\hline B2PLYP & 53 & 7.7 & -20.1 & 1.3 & $-25.4(-29.9)$ \\
\hline B2PLYP-D3 & 53 & 7.2 & -20.4 & 0.9 & $-25.6(-30.1)$ \\
\hline LC- $\omega$ PBE & $0-100$ & 7.8 & -23.6 & 2.2 & $-26.4(-30.4)$ \\
\hline$\omega \mathrm{B} 97 \mathrm{XD}$ & $0-100$ & 8.6 & -23.9 & 3.4 & $-26.1(-30.2)$ \\
\hline
\end{tabular}

Notes. The percentage of HF exchange of the functionals is also indicated. Conversion factors: $1 \mathrm{kcal} \mathrm{mol}^{-1}=349.7 \mathrm{~cm}^{-1}=503.2 \mathrm{~K}$ ${ }^{(a)}$ Reaction enthalpy for the $(\mathrm{Z})$ isomer; in parenthesis, for the $(\mathrm{E})$ isomer. ${ }^{(b)}$ Single point at the MP2/aug-cc-pVTZ geometry.

considering only the first step of reaction a (Table 5). The first conclusion to be drawn is that, by comparing with $\operatorname{CCSD}(\mathrm{T})$ results, the errors observed for MP2 and B3LYP remain in the same proportion for both the gas phase and icy environment. Thus, ignoring the B3LYP and MP2 calculations, the general effect of embedding in the ice is to increase the activation barrier within $\sim 1.5 \mathrm{kcal} \mathrm{mol}^{-1}$ and to make the reaction less exothermic by $\sim 2.5 \mathrm{kcal} \mathrm{mol}^{-1}$.

The same general conclusions can be drawn for all the DFT computational treatments. The best compromise is obtained using the M06-2X functional. But for the chemical aspects, $\mathrm{CH}_{3} \mathrm{CN}$ is very different from $\mathrm{CH}_{3} \mathrm{NC}$. Indeed, at this level the activation barrier on path $b$ is found to be nearly three times smaller than for path a.

In the end, we present the reactions profiles of path a and $\mathrm{b}$ as obtained in the M06-2X/aug-cc-pVTZ framework. In addition, this treatment can be applied to a chemical problem of large dimensions. This approach has the further advantage of being extended to gas-solid catalytic interactions if needed.

\subsection{Probing the reaction paths}

Formation of ethylamine and dimethylamine requires additions of four hydrogen atoms, which means four successive elementary steps for each reaction path. It should be mentioned that only the thermodynamically a priori most probable reaction paths were considered, i.e., those for which each step gives rise to the more stable product (Table 6).
Table 5. Reaction enthalpy $(\Delta H)$ and activation barrier $\left(\Delta H^{\dot{亠}}\right)$, corrected for ZPE, of the hydrogen addition reaction to $\mathrm{CH}_{3} \mathrm{CN}$, calculated at $0 \mathrm{~K}$ at the MP2, CCSD(T) and DFT level with the aug-cc-pVTZ basis set, in vacuum and in ice $\left(\mathrm{kcal} \mathrm{mol}^{-1}\right)$.

\begin{tabular}{lcccc}
\hline \hline \multirow{2}{*}{$\begin{array}{l}\text { Level } \\
\text { of theory }\end{array}$} & \multicolumn{2}{c}{ No ice involvement } & \multicolumn{2}{c}{ Embedded in ice } \\
& $\Delta H^{\ddagger}$ & $\Delta H$ & $\Delta H^{\ddagger}$ & $\Delta H$ \\
\hline MP2 & 21.8 & -4.7 & 21.6 & -3.8 \\
CCSD(T) ${ }^{(a)}$ & 9.2 & -18.7 & 9.9 & -16.8 \\
\hline B3LYP & 5.2 & -24.6 & 6.6 & -21.8 \\
MPWB1K & 7.6 & -22.1 & 8.3 & -20.0 \\
M06-2X & 7.9 & -20.2 & 9.3 & -17.3 \\
B2PLYP & 7.7 & -20.1 & 8.9 & -17.6 \\
B2PLYPD3 & 7.2 & -20.4 & 8.4 & -17.9 \\
LC-wPBE & 7.8 & -23.6 & 9.2 & -20.9 \\
wB97XD & 8.6 & -23.9 & 10.0 & -21.1 \\
\hline
\end{tabular}

Notes. Conversion factors: $1 \mathrm{kcal} \mathrm{mol}-1=349.7 \mathrm{~cm}^{-1}=503.2 \mathrm{~K}$. ${ }^{(a)}$ Single point at the MP2 geometry (CCSD gradients are not available in the framework of the PCM model).

Table 6. Energy profiles of reaction paths $a$ and $b$ in vacuum and in ice.

\begin{tabular}{lcccc}
\hline \hline \multirow{2}{*}{ Reactions } & \multicolumn{2}{c}{ No ice involvement } & \multicolumn{2}{c}{ Embedded in ice } \\
& $\Delta H^{\#}$ & $\Delta H$ & $\Delta H^{\#}$ & $\Delta H$ \\
\hline Reaction path a & & & & \\
$\mathrm{CH}_{3} \mathrm{CN}+\mathrm{H}^{\bullet} \rightarrow \mathrm{CH}_{3} \mathrm{CHN}^{\bullet}$ & 7.9 & -20.2 & 9.3 & -17.4 \\
$\mathrm{CH}_{3} \mathrm{CHN}+\mathrm{H}^{\bullet} \rightarrow(\mathrm{E})-\mathrm{CH}_{3} \mathrm{CHNH}$ & $/^{(a)}$ & -88.1 & $/^{(a)}$ & -88.1 \\
$(\mathrm{E})-\mathrm{CH}_{3} \mathrm{CHNH}+\mathrm{H}^{\bullet} \rightarrow \mathrm{CH}_{3} \mathrm{CHNH}_{2}$ & 4.1 & -34.1 & 4.7 & -32.3 \\
$\mathrm{CH}_{3} \mathrm{CHNH}_{2}^{*}+\mathrm{H}^{\bullet} \rightarrow \mathrm{CH}_{3} \mathrm{CH}_{2} \mathrm{NH}_{2}$ & $/^{(a)}$ & -88.9 & $/^{(a)}$ & -89.1 \\
\hline Reaction path b & & & & \\
$\mathrm{CH}_{3} \mathrm{NC}+\mathrm{H}^{\bullet} \rightarrow(\mathrm{Z})-\mathrm{CH}_{3} \mathrm{NCH}^{\bullet}$ & 2.9 & -22.6 & 3.8 & -20.3 \\
$(\mathrm{Z})-\mathrm{CH}_{3} \mathrm{NCH}^{\bullet} \rightarrow(\mathrm{E})-\mathrm{CH}_{3} \mathrm{NCH}^{\bullet}$ & 10.3 & -4.1 & 10.3 & -2.9 \\
$(\mathrm{E})-\mathrm{CH}_{3} \mathrm{NCH}^{\bullet}+\mathrm{H}^{\bullet} \rightarrow \mathrm{CH}_{3} \mathrm{NCH}_{2}$ & $/^{(a)}$ & -94.8 & $/^{(a)}$ & -96.3 \\
$\mathrm{CH}_{3} \mathrm{NCH}_{2}+\mathrm{H}^{\bullet} \rightarrow \mathrm{CH}_{3} \mathrm{NHCH}_{2}$ & 4.5 & -34.9 & 5.0 & -34.1 \\
$\mathrm{CH}_{3} \mathrm{NHCH}_{2}+\mathrm{H}^{\bullet} \rightarrow \mathrm{CH}_{3} \mathrm{NHCH}_{3}$ & $/^{(a)}$ & -89.8 & $/^{(a)}$ & -89.7 \\
\hline
\end{tabular}

Notes. Exothermicity $(\Delta H)$ and activation barrier $\left(\Delta H^{\#}\right)$ corrected for ZPE $\left(\mathrm{kcal} \mathrm{mol}^{-1}\right)$ as obtained at the M06-2X/aug-cc-pVTZ level. Conversion factors: $1 \mathrm{kcal} \mathrm{mol}^{-1}=349.7 \mathrm{~cm}^{-1}=503.2 \mathrm{~K}$. ${ }^{(a)}$ No activation barrier.

On the way to $\mathrm{CH}_{3} \mathrm{CH}_{2} \mathrm{NH}_{2}$ on path a, the first addition leads to the formation of $\mathrm{CH}_{3} \mathrm{CH}=\mathrm{N}^{\bullet}$, a free radical of the same type as $\mathrm{H}_{2} \mathrm{C}=\mathrm{N}$ detected by Ohishi et al. (1994). This is an exothermic process over approximately $-20 \mathrm{kcal} \mathrm{mol}^{-1}$, which is however opposed by an activation barrier of $\sim 8 \mathrm{kcal} \mathrm{mol}^{-1}$. Addition on nitrogen leading to $\mathrm{CH}_{3} \mathrm{C}=\mathrm{NH}$ is also exothermic, but only by $11 \mathrm{kcal} \mathrm{mol}^{-1}$, and presents an even greater activation barrier $\left(9.3 \mathrm{kcal} \mathrm{mol}^{-1}\right)$; thus, this process and those stemming from are not considered. The second elementary step is a radical-radical 
reaction without activation barrier leading to $(\mathrm{E})-\mathrm{CH}_{3} \mathrm{CH}=\mathrm{NH}$ similar to methanimine (Godfrey et al. 1973). The third hydrogenation leads to a second free radical, (E)- $\mathrm{CH}_{3} \mathrm{CHNH}_{2}^{\bullet}$ centered on the carbon. There is an activation barrier of $\sim 4 \mathrm{kcal} \mathrm{mol}^{-1}$. The fourth step completes the reaction path to ethylamine without any transition state. Both the second and fourth steps are strongly exothermic, by about $90 \mathrm{kcal} \mathrm{mol}^{-1}$. The height of the first activation barrier should be considered as a real obstacle.

The presence of ice does not modify the exothermicity of the radical-radical steps, but slightly decreases it in the first and third steps (by $\sim 3$ and $\sim 2 \mathrm{kcal} \mathrm{mol}^{-1}$, respectively). Moreover both activation barriers increase, the first by $1.4 \mathrm{cal} \mathrm{mol}^{-1}$, thus rendering the hydrogenation reaction of $\mathrm{CH}_{3} \mathrm{CN}$ even less favorable.

On the way to $\mathrm{CH}_{3} \mathrm{NHCH}_{3}$ on path $\mathrm{b}$, we find the same sequence of reactions. The radical formed in the first step, $\mathrm{CH}_{3} \mathrm{~N}=\mathrm{CH}^{\bullet}$, can exist in the forms of $(\mathrm{E})$ and $(\mathrm{Z})$ isomers, both being stable intermediates. They are both produced (Table 6) in exothermic processes, $\Delta H \sim-27 \mathrm{kcal} \mathrm{mol}^{-1}$ and $\Delta H \sim$ $-23 \mathrm{kcal} \mathrm{mol}^{-1}$ for (E) and (Z), respectively. Reaching the transition state requires only $\sim 3 \mathrm{kcal} \mathrm{mol}^{-1}$, that is a small activation energy compared to that of the first step in path a. Therefore, hydrogenation of $\mathrm{CH}_{3} \mathrm{NC}$ is probable, at least by tunneling through a small barrier, while hydrogenation of $\mathrm{CH}_{3} \mathrm{CN}$ is not. This result is consistent with the so-called Fukui indices that rationalize the rules of frontier molecular orbital theory (Fukui et al. 1952), which is relevant to interpret radical reactivity. Indeed, following the procedure of Bulat et al. (2004) we obtain, for the carbon atom in the $\mathrm{CN}$ (or NC) group, 0.17 and 0.70 in $\mathrm{CH}_{3} \mathrm{CN}$ and in $\mathrm{CH}_{3} \mathrm{NC}$, respectively (the greater the index, the faster the reactivity with $\mathrm{H}$ atoms).

A detailed study of the reaction path using the intrinsic reaction coordinate technique showed that the transition state connects preferentially to the less stable ( $Z$ ) isomer, which can transform easily into (E). Indeed, the activation barrier of the transformation $(\mathrm{Z}) \rightarrow(\mathrm{E})$ is only a hidden barrier at this stage.

The second elementary step is a radical-radical reaction without activation barrier leading to $\mathrm{CH}_{3} \mathrm{~N}=\mathrm{CH}_{2}$. Further addition of a hydrogen atom produces a new radical intermediate $\mathrm{CH}_{3} \mathrm{NH}-\mathrm{CH}_{2}^{\bullet}$ that is exothermic (approximately $-35 \mathrm{kcal} \mathrm{mol}^{-1}$ ) and also opposed by a small barrier of $\sim 4.5 \mathrm{kcal} \mathrm{mol}^{-1}$. In the end the last step is barrier free and leads to dimethylamine, $\mathrm{CH}_{3} \mathrm{NHCH}_{3}$. As in path a radical-radical reactions are strongly exothermic, by about $90 \mathrm{kcal} \mathrm{mol}^{-1}$.

The presence of ice has the same effects as for path a, though attenuated. In particular, the first barrier to hydrogenation increases slightly, reaching $3.8 \mathrm{kcal} \mathrm{mol}^{-1}$. If tunneling is still possible, our calculations predict that it should be less facile, which does not seem to be in agreement with the experiments.

\section{Comparison with astronomical observations}

We investigate the presence of $\mathrm{CH}_{3} \mathrm{NH}_{2}$ along with that of the $\mathrm{C}_{2} \mathrm{H}_{5} \mathrm{NH}_{2}$ amine and that of the possible parent molecules, $\mathrm{CH}_{3} \mathrm{CN}$ and $\mathrm{CH}_{3} \mathrm{NC}$ in the ISM; spectroscopic data of $\left(\mathrm{CH}_{3}\right)_{2} \mathrm{NH}$ are not available at the present time in the (sub)millimeter wavelength. More specifically, we search for these species toward the high-mass star forming region W51/e2 (located at $5.4 \mathrm{kpc}$, Sato et al. 2010), in which the presence of methyl cyanide has been reported by Remijan et al. (2004). In the present study, we make use of IRAM $30 \mathrm{~m}$ observations that we have available (PI C. Favre) and that cover the following frequency ranges: $99.70-106.3 \mathrm{GHz}$ and $238.2-246.0 \mathrm{GHz}$. We refer to Lykke et al. (2015) for a full description of the observations and data reduction.

In this paper, we focus on $\mathrm{CH}_{3} \mathrm{CN}$ and $\mathrm{CH}_{3} \mathrm{NC}$ transitions with an upper energy level, $E_{\text {up }}$, up to $660 \mathrm{~K}$, and search for $\mathrm{C}_{2} \mathrm{H}_{5} \mathrm{NH}_{2}$ and $\mathrm{CH}_{3} \mathrm{NH}_{2}$ transitions with an Einstein coefficient, A, greater than $5 \times 10^{-5} \mathrm{~s}^{-1}$. Tables B.1-B.4 give the spectroscopic and observational line parameters for $\mathrm{CH}_{3} \mathrm{CN}$, $\mathrm{CH}_{3} \mathrm{NC}, \mathrm{C}_{2} \mathrm{H}_{5} \mathrm{NH}_{2}$, and $\mathrm{CH}_{3} \mathrm{NH}_{2}$, respectively. We detect five lines and observed two partially blended and two blended lines for $\mathrm{CH}_{3} \mathrm{CN}$. The mean velocity is around $55.6 \mathrm{~km} \mathrm{~s}^{-1}$, which is consistent with the systemic velocity of the source, and the mean line width, $\Delta v_{1 / 2}$, is about $8 \mathrm{~km} \mathrm{~s}^{-1}$ (see Table B.1). We do not detect $\mathrm{CH}_{3} \mathrm{NC}, \mathrm{C}_{2} \mathrm{H}_{5} \mathrm{NH}_{2}$ nor $\mathrm{CH}_{3} \mathrm{NH}_{2}$ : their respective lines are either not detected or are blended with the emission from another species. The observed W51/e 2 spectra for the targeted molecules are shown in Fig. 10.

From the rotational population diagram method (see Turner 1991; Goldsmith \& Langer 1999), we can estimate the physical properties $(\mathrm{T}, \mathrm{N})$ of the detected $\mathrm{CH}_{3} \mathrm{CN}$ molecule. This analysis hinges upon the assumptions that local thermodynamical equilibrium (LTE) is reached (i.e. the kinetic, excitation, and rotational temperatures are equal) and that the lines are optically thin. Following Goldsmith \& Langer (1999), we estimate that the $\mathrm{CH}_{3} \mathrm{CN}$ emission is optically thin with $\tau \leqslant 0.2$. In addition, in the present study, we assume that the emission comes from a source size that is equal to the beam size $\left(\sim 10^{\prime}\right.$ at $1 \mathrm{~mm}$ ). The rotational population diagram analysis yields to a rotational temperature for $\mathrm{CH}_{3} \mathrm{CN}$ of $T_{\text {rot }}=(343 \pm 43) \mathrm{K}$. The derived beam-averaged total $\mathrm{CH}_{3} \mathrm{CN}$ column density ${ }^{5}, N_{\mathrm{CH}_{3} \mathrm{NC}}$, is $(1.5 \pm 0.2) \times 10^{15} \mathrm{~cm}^{-2}$.

Regarding the nondetected species, assuming the same rotational temperature $\left(T_{\text {rot }}=300 \mathrm{~K}\right)$ as that derived from the $\mathrm{CH}_{3} \mathrm{CN}$ study, we estimate the following upper limits on their beam-averaged column densities: $N_{\left(\mathrm{CH}_{3} \mathrm{NC}\right)} \leq 9.8 \times 10^{13} \mathrm{~cm}^{-2}$, $N_{\left(\mathrm{C}_{2} \mathrm{H}_{5} \mathrm{NH}_{2}\right)} \leq 1.8 \times 10^{15} \mathrm{~cm}^{-2}$, and $N_{\left(\mathrm{CH}_{3} \mathrm{NH}_{2}\right)} \leq 4 \times 10^{15} \mathrm{~cm}^{-2}$.

To summarize, we find that $\mathrm{CH}_{3} \mathrm{NC}$ is at least 15 times less abundant than $\mathrm{CH}_{3} \mathrm{CN}$, while ethylamine and methylamine could have an abundance of the same order of magnitude as $\mathrm{CH}_{3} \mathrm{CN}$.

\section{Concluding remarks}

Experiments have shown that $\mathrm{CH}_{3} \mathrm{CN}$ does not react with $\mathrm{H}$ atoms. Calculations have confirmed that the hydrogenation barrier of the first hydrogenation is high and makes starting the chemical process leading to the primary amine unlikely. It should be noted that the reduction of $\mathrm{CH}_{3} \mathrm{CN}$, and therefore the reactivity with hydrogen atoms, has been observed in UV photolysis experiments of this molecule (e.g., Hudson \& Moore 2004). Our experiment differs from previous approaches because we use atoms thermalized with the surface and because most of the highest energy reactive paths are not efficient under our experimental conditions. The calculated barrier is too high for our experimental conditions, whether by direct thermal crossing or by tunnel effect; this barrier, is reachable by $\mathrm{H}$ atoms, which would have a higher initial kinetic energy, for example, after the photolysis of $\mathrm{CH}_{3} \mathrm{CN}$.

On the contrary, $\mathrm{CH}_{3} \mathrm{NC}$ reacts with $\mathrm{H}$ and forms $\mathrm{CH}_{3} \mathrm{NCH}_{2}$, $\mathrm{CH}_{3} \mathrm{NHCH}_{3}$, which have been identified as the most stable

5 We obtain $N_{\mathrm{CH}_{3} \mathrm{NC}}$ assuming a rotational temperature of $300 \mathrm{~K}$ as the Jet Propulsion Laboratory (JPL) catalog provides a line partition function for this species that is only valid up to $300 \mathrm{~K}$. Nonetheless, we note that the assumed value is commensurate within the error bars with the value we derived in this study. 

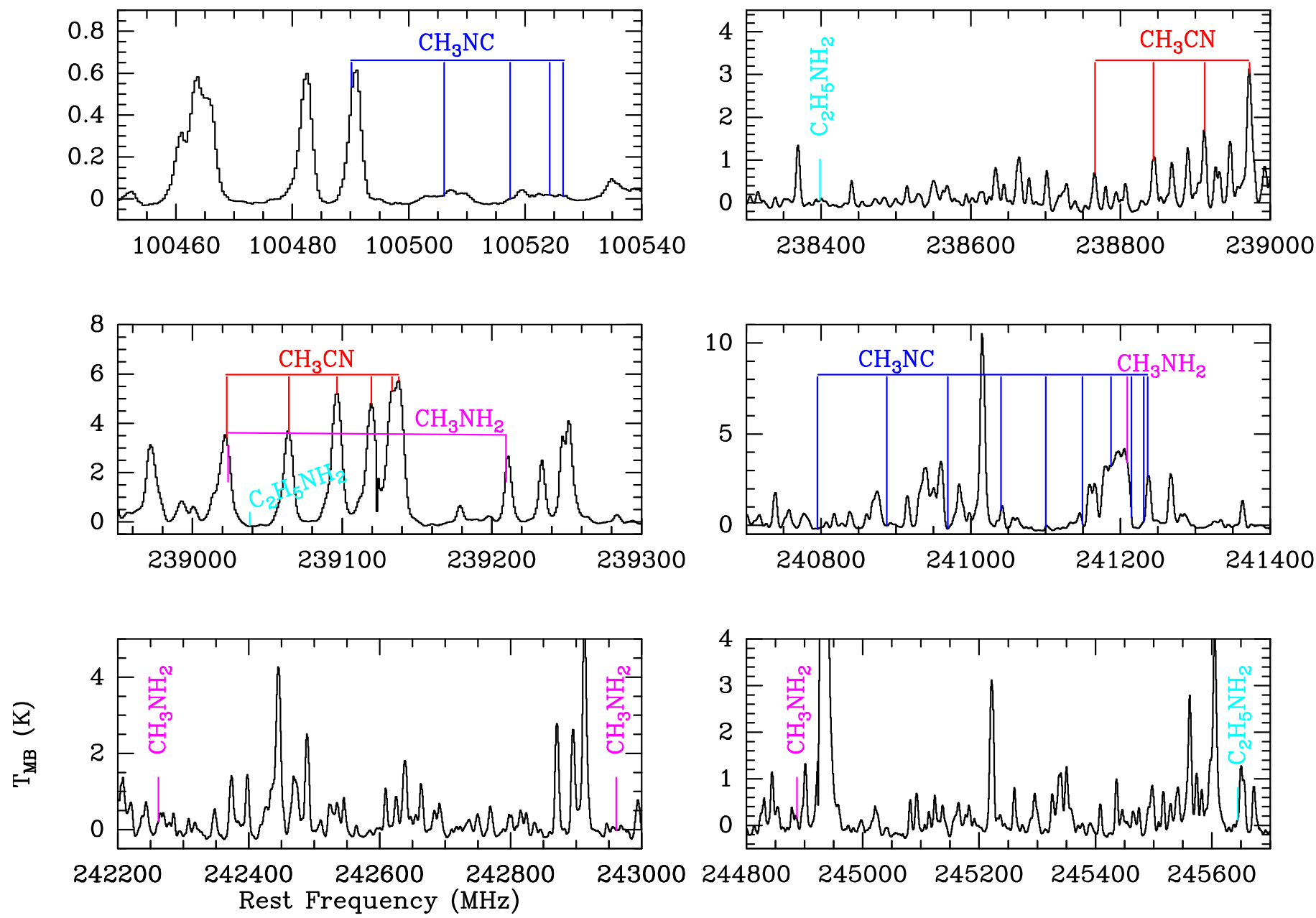

Fig. 10. Portion of the W51/e2 spectra as observed at 1 and $3 \mathrm{~mm}$ with the IRAM $30 \mathrm{~m}$ telescope. Line assignmentd of $\mathrm{CH}_{3} \mathrm{CN}_{(\mathrm{red}), \mathrm{CH}_{3} \mathrm{NC}}$ (blue), $\mathrm{C}_{2} \mathrm{H}_{5} \mathrm{NH}_{2}$ (cyan), and $\mathrm{CH}_{3} \mathrm{NH}_{2}$ (magenta) are indicated on top of the spectra.

products along the hydrogenation process. The detection of $\mathrm{CH}_{3} \mathrm{NCH}_{2}$ is in agreement with the decrease of the calculated activation barrier of the first hydrogenation going from $\mathrm{CH}_{3} \mathrm{CN}$ to $\mathrm{CH}_{3} \mathrm{NC}$, showing that the starting of the chemical process is easier. Methane $\left(\mathrm{CH}_{4}\right)$ and $\mathrm{HCN}$ have been also identified but only as collateral products of much lower abundance.

The different reactivity of $\mathrm{CH}_{3} \mathrm{NC}$ and $\mathrm{CH}_{3} \mathrm{CN}$ is a possible explanation for the observed ratio of $\mathrm{CH}_{3} \mathrm{NC}$ and $\mathrm{CH}_{3} \mathrm{CN}$ factor of 0.03-0.05 (Cernicharo et al. 1988), which is less than expected by pure gas-phase routes. Indeed, $\mathrm{CH}_{3} \mathrm{NC}$ and $\mathrm{CH}_{3} \mathrm{CN}$ have a different fate on the surface of grains. $\mathrm{CH}_{3} \mathrm{NC}$ likely evolves under hydrogenation, whereas $\mathrm{CH}_{3} \mathrm{CN}$ is unaffected by hydrogenation, which is the main chemical driving force for surface reactivity in molecular clouds. So, if part of the mantle is feeding the gas phase, as occurs in shocks or hot cores, thus chemical differentiation on grains can induce differences in the gas phase. As highlighted by TPD experiments $\mathrm{CH}_{3} \mathrm{NC}$ does not react with $\mathrm{H}_{2} \mathrm{O}$ but is trapped in $\mathrm{H}_{2} \mathrm{O}$.

In addition, hydrogenation of $\mathrm{CH}_{3} \mathrm{NC}$ is enhanced in the presence of $\mathrm{H}_{2} \mathrm{O}$. More specifically, when $\mathrm{CH}_{3} \mathrm{NC}$ and $\mathrm{H}$ atoms mix with the $\mathrm{H}_{2} \mathrm{O}$ molecules, the chemical reactions take place inside the pores or in the bulk of the ice. The water molecules therefore may increase the efficiency of quantum tunneling in the hydrogenation process of $\mathrm{CH}_{3} \mathrm{NC}$.

At low temperatures, $\mathrm{CH}_{3} \mathrm{NC}$ should react with $\mathrm{H}$ atoms via quantum tunneling. At high temperatures, the reactions of
$\mathrm{CH}_{3} \mathrm{NC}$ take place with temperature effect adding to tunneling. However, a temperature dependence out of the Arrhenius regime would be the final argument to ensure that the first step of the reaction is actually achieved by quantum tunneling. We base our conclusions on the observed isotope effect, temperature dependence, and calculation of the height of the reaction barrier. We note that taken separately our arguments might appear weak. However, once combined together they are stronger and represent the best we can currently do to build our conviction.

To summarize, the hydrogenation is enhanced with the $\mathrm{H}_{2} \mathrm{O}$ presence, although there is no evidence of a chemical participation in the calculations. In this context, the fact that our calculations show an increase of the first activation barrier is not compatible with the experimental facts, even if the barrier of the first hydrogenation of $\mathrm{CH}_{3} \mathrm{NC}$ remains lower than that of the third hydrogenation. Modeling solid water by an implicit solvent, originally proposed for disordered liquid media, is therefore questionable. The answer is to be found in the neglect of local interactions with the well-defined structure of ice; porous does not mean disordered at the local scale. Taking into account well-oriented local interactions, namely the hydrogen bonds in the solid, can be done in solid state calculations (Lattelais et al. 2011; Bertin et al. 2017). Such a treatment as presented for the trapping of small molecules in cometary ice (Mousis et al. 2016, 2017) and Europa ice crust (Ozgurel et al. 2018) is well beyond the aim of the present work. 
In the presence of $\mathrm{H}_{2} \mathrm{O}$, the easier hydrogenation of $\mathrm{CH}_{3} \mathrm{NC}$ may be due to different electronic properties. In terms of quantum chemistry, it may affect the geometry of the reaction and thereby lower the reaction barrier. Water can also slightly change the geometry of the molecule $\mathrm{CH}_{3} \mathrm{NC}$ itself, and/or displace slightly charges changing the heights of the reaction barriers. Water molecules could also participate by helping proton transfer (Rimola et al. 2014). It should also be stressed that the above developments are valid for all the R-CN nitriles (as quoted in Sect. 1), but limited for R-NC isonitriles since the hydrogenation can only provide $\mathrm{N}$-methyl substituted secondary amines.

Under astrophysical conditions, the flux of $\mathrm{H}$ atoms is orders of magnitude lower than in our experimental conditions. Therefore, the $\mathrm{H}$ concentration on the surface is also lower, and therefore the $\mathrm{H}+\mathrm{H} \longrightarrow \mathrm{H}_{2}$, is less competitive than in our experimental conditions. We have seen that even under our "high" flux conditions, hydrogenation of $\mathrm{CH}_{3} \mathrm{NC}$ is efficient, so it should also be the case in dense molecular clouds. On the contrary, if the temperature of the grain rises above $20 \mathrm{~K}$, thus the hydrogenation efficiency drops and dimethyl amine has probably very little chance to be formed this way.

In the end, the present interdisciplinary study mixing experimental and theoretical aspects of laboratory astrophysics together with tentative detection of simple primary and secondary amines leads to some suggestions for observation proposals. Finding $\mathrm{CH}_{3} \mathrm{NHCH}_{3}$ would need more refined spectra. The detection of $\mathrm{CH}_{3} \mathrm{CH}_{2} \mathrm{NH}_{2}$ seems much less plausible if, as considered in this work, it comes from nitrile hydrogenation. Thus, another route to the formation of amines has to be found. For example we could consider the hydrogenation of imines, assuming the latter are obtained by a mechanism different from hydrogenation of nitriles.

Acknowledgements. This work was supported by the Programme National "Physique et Chimie du Milieu Interstellaire" (PCMI) of CNRS/INSU with INC/INP co-funded by CEA and CNES and the DIM ACAV+, a funding program of the Region Ile de France. T.N. thanks the LabEx MICHEM for her $\mathrm{PhD}$ grant. This work is also supported by the French National Research Agency in the framework of the Investissements d'Avenir program (ANR-15-IDEX-02). C.F. acknowledges support from the European Research Council (ERC) under the European Union's Horizon 2020 research and innovation programme, for the Project "The Dawn of Organic Chemistry" (DOC), grant agreement No 741002. I.F. is greatful to P. Chaquin and B. Silvi for fruitful discussions about reactivity.

\section{References}

Amiaud, L., Dulieu, F., Fillion, J.-H., Momeni, A., \& Lemaire, J. L. 2007 J. Chem. Phys., 127, 144709

Anttila, R., Horneman, V. M., Koivusaari, M., \& Paso, R. 1993, J. Mol. Spectr., 157, 198

Apponi, A. J., Sun, M., Halfen, D. T., Ziurys, L. M., \& Müller, H. S. P. 2008, ApJ, 673, 1240

Bauder, A., \& Bogey, M. 1970, R. Acad. Sci. Ser. B, 271

Becke, A. D. 1993, J. Chem. Phys., 98, 5648

Belloche, A., Garrod, R. T., Müller, H. S. P., et al. 2009, A\&A, 499, 215

Belloche, A., Garrod, R. T., Müller, H. S. P., \& Menten, K. M. 2014, Science, 345,1584

Belloche, A., Müller, H. S. P., Garrod, R. T., \& Menten, K. M. 2016, A\&A, 587, A91

Bertin, M., Doronin, M., Fillion, J.-H., et al. 2017, A\&A, 598, A18

Bisschop, S. E., Fuchs, G. W., van Dishoeck, E. F., \& Linnartz, H. 2007, A\&A 474, 1061

Boucher, D., Burie, J., Demaison, J., et al. 1977, J. Mol. Spectr., 64, 290

Bulat, F. A., Chamorro, E., Fuentealba, P., \& Toro-Labbé, A. 2004, J. Phys. Chem. A, 108, 342

Cazzoli, G., \& Puzzarini, C. 2006, J. Mol. Spectr., 240, 153

Cernicharo, J., Kahane, C., Guelin, M., \& Gomez-Gonzalez, J. 1988, A\&A, 189 L1
Chaabouni, H., Diana, S., Nguyen, T., \& Dulieu, F. 2018, A\&A, 612, A47 Chai, J.-D., \& Head-Gordon, M. 2008, Phys. Chem. Chem. Phys., 10, 6615 Collings, M. P., Anderson, M. A., Chen, R., et al. 2004, MNRAS, 354, 1133 Congiu, E., Matar, E., Kristensen, L. E., Dulieu, F., \& Lemaire, J. L. 2009, MNRAS, 397, L96

Congiu, E., Fedoseev, G., Ioppolo, S., et al. 2012, ApJ, 750, L12

Defrees, D. J., McLean, A. D., \& Herbst, E. 1985, ApJ, 293, 236

Dulieu, F., Congiu, E., Noble, J., et al. 2013, Sci. Rep., 3, 1338

Dulieu, F., Minissale, M., \& Bockelée-Morvan, D. 2017, A\&A, 597, A56

Dulieu, F., Nguyen, T., Congiu, E., Baouche, S., \& Taquet, V. 2019, MNRAS, 484, L119

Dunning, T. H. 1989, J. Chem. Phys., 90, 1007

Duvernay, F., Danger, G., Theulé, P., Chiavassa, T., \& Rimola, A. 2014, ApJ, 791, 75

Fischer, E., \& Botskor, I. 1982, J. Mol. Spectr., 91, 116

Fischer, E., \& Botskor, I. 1984, J. Mol. Spectr., 104, 226

Friedel, D. N., Snyder, L. E., Turner, B. E., \& Remijan, A. 2004, ApJ, 600, 234

Frisch, M., Trucks, G., Schlegel, H., et al. 2009, Gaussian 09, Revision B.01, Gaussian, Inc., Wallingford CT

Fukui, K., Yonezawa, T., \& Shingu, H. 1952, J. Chem. Phys., 20, 722

Gadhi, J., Lahrouni, A., Legrand, J., \& Demaison, J. 1995, J. Chim. Phys., 92. 1984

Gardner, F. F., \& Winnewisser, G. 1975, ApJ, 195, L127

Godfrey, P. D., Brown, R. D., Robinson, B. J., \& Sinclair, M. W. 1973, Astrophys. Lett., 13, 119

Goldsmith, P. F., \& Langer, W. D. 1999, ApJ, 517, 209

Gratier, P., Pety, J., Guzmán, V., et al. 2013, A\&A, 557, A101

Grimme, S. 2006, J. Chem. Phys., 124, 034108

Grimme, S., Ehrlich, S., \& Goerigk, L. 2011, J. Comput. Chem., 32, 1456

Hama, T., Kuwahata, K., Watanabe, N., et al. 2012, ApJ, 757, 185

Hiraoka, K., Wada, A., Kitagawa, H., et al. 2005, ApJ, 620, 542

Hudson, R. L., \& Moore, M. H. 2004, Icarus, 172, 466

Ilyushin, V. V., Alekseev, E. A., Dyubko, S. F., Motiyenko, R. A., \& Hougen, J. T. 2005, J. Mol. Spectr., 229, 170

Ioppolo, S., Cuppen, H. M., van Dishoeck, E. F., \& Linnartz, H. 2011, MNRAS, 410, 1089

Irvine, W. M., \& Schloerb, F. P. 1984, ApJ, 282, 516

Jiménez-Serra, I., Vasyunin, A. I., Caselli, P., et al. 2016, ApJ, 830, L6

Johari, G. P., \& Jones, S. J. 1976, Proc. Royal Soc. Lond. A, 349, 467

Johnson, D. R., Lovas, F. J., Gottlieb, C. A., et al. 1977, ApJ, 218, 370

Kaifu, N., Morimoto, M., Nagane, K., et al. 1974, ApJ, 191, L135

Kawaguchi, K., Ohishi, M., Ishikawa, S.-I., \& Kaifu, N. 1992, ApJ, 386, L51

Kréglewski, M., \& Wlodarczak, G. 1992, J. Mol. Spectr., 156, 383

Krȩglewski, M., Stahl, W., Grabow, J.-U., \& Wlodarczak, G. 1992, Chem. Phys. Lett., 196, 155

Kukolich, S. G. 1982, J. Chem. Phys., 76, 97

Kukolich, S. G., Ruben, D. J., Wang, J. H. S., \& Williams, J. R. 1973, J. Chem. Phys., 58, 3155

Lattelais, M., Pauzat, F., Ellinger, Y., \& Ceccarelli, C. 2009, ApJ, 696, L133

Lattelais, M., Bertin, M., Mokrane, H., et al. 2011, A\&A, 532, A12

Lee, C., Yang, W., \& Parr, R. G. 1988, Phys. Rev. B, 37, 785

Lide, Jr. D. R. 1954, J. Chem. Phys., 22, 1613

Lide, Jr. D. R. 1957, J. Chem. Phys., 27, 343

López, A., Tercero, B., Kisiel, Z., et al. 2014, A\&A, 572, A44

Lykke, J. M., Favre, C., Bergin, E. A., \& Jørgensen, J. K. 2015, A\&A, 582, A64

Margulès, L., Belloche, A., Müller, H. S. P., et al. 2016, A\&A, 590, A93

McGuire, B. A. 2018, ApJS, 239, 17

McGuire, B. A., Burkhardt, A. M., Kalenskii, S., et al. 2018, Science, 359, 202

Mencos, A., \& Krim, L. 2016, MNRAS, 460, 1990

Minissale, M., Moudens, A., Baouche, S., Chaabouni, H., \& Dulieu, F. 2016, MNRAS, 458, 2953

Minissale, M., Nguyen, T., \& Dulieu, F. 2019, A\&A, 622, A148

Møller, C., \& Plesset, M. S. 1934, Phys. Rev., 46, 618

Mousis, O., Ronnet, T., Brugger, B., et al. 2016, ApJ, 823, L41

Mousis, O., Ozgurel, O., Lunine, J. I., et al. 2017, ApJ, 835, 134

Müller, H. S. P., Schlöder, F., Stutzki, J., \& Winnewisser, G. 2005, J. Mol Spectr., 742, 215

Murphy, K., Azad, S., Bennett, D., \& Tysoe, W. 2000, Surf. Sci., 467, 1

Nguyen, T., Baouche, S., Congiu, E., et al. 2018, A\&A, 619, A111

Nishikawa, T. 1957, J. Phys. Soc. Jpn., 12, 668

Nummelin, A., Bergman, P., Hjalmarson, A., et al. 1998, ApJS, 117, 427

Ohashi, N., Takagi, K., Hougen, J. T., Olson, W. B., \& Lafferty, W. J. 1987, J. Mol. Spectr., 126, 443

Ohishi, M., McGonagle, D., Irvine, W. M., Yamamoto, S., \& Saito, S. 1994, ApJ, 427, L51 
Ozgurel, O., Mousis, O., Pauzat, F., et al. 2018, ApJ, 865, L16

Pickett, H. M., Poynter, I. R. L., Cohen, E. A., et al. 1998, J. Quant. Spectr. Rad. Transf., 60, 883

Purvis, G. D., \& Bartlett, R. J. 1982, J. Chem. Phys., 76, 1910

Raghavachari, K., Trucks, G. W., Pople, J. A., \& Head-Gordon, M. 1989, Chem. Phys. Lett., 157, 479

Remijan, A., Sutton, E. C., Snyder, L. E., et al. 2004, ApJ, 606, 917

Remijan, A. J., Hollis, J. M., Lovas, F. J., Plusquellic, D. F., \& Jewell, P. R. 2005 , ApJ, 632, 333

Rimola, A., Taquet, V., Ugliengo, P., Balucani, N., \& Ceccarelli, C. 2014, A\&A, 572, A70

Sandford, S. A., Aléon, J., Alexander, C. M. O., et al. 2006, Science, 314 1720

Sato, M., Reid, M. J., Brunthaler, A., \& Menten, K. M. 2010, ApJ, 720, 1055

Shimoda, K., Nishikawa, T., \& Itoh, T. 1954, J. Phys. Soc. Jpn., 9, 974

Solomon, P. M., Jefferts, K. B., Penzias, A. A., \& Wilson, R. W. 1971, ApJ, 168, L107
Speedy, R. J., Debenedetti, P. G., Smith, R. S., Huang, C., \& Kay, B. D. 1996, J. Chem. Phys., 105, 240

Takagi, K., \& Kojima, T. 1971, J. Phys. Soc. Jpn., 30, 1145

Talbi, D., \& Ellinger, Y. 1996, Chem. Phys. Lett., 263, 385

Talbi, D., Ellinger, Y., \& Herbst, E. 1996, A\&A, 314, 688

Theulé, P., Borget, F., Mispelaer, F., et al. 2011, A\&A, 534, A64

Theulé, P., Duvernay, F., Danger, G., et al. 2013, Adv. Space Res., 52, 1567

Tomasi, J., \& Persico, M. 1994, Chem. Rev., 94, 2027

Turner, B. E. 1971, ApJ, 163, L35

Turner, B. E. 1991, ApJS, 76, 617

Vydrov, O. A., \& Scuseria, G. E. 2006, J. Chem. Phys., 125, 234109

Wakelam, V., Bron, E., Cazaux, S., et al. 2017, Mol. Astrophys., 9, 1

Watanabe, N., Nagaoka, A., Shiraki, T., \& Kouchi, A. 2004, ApJ, 616, 638

Zhao, Y., \& Truhlar, D. G. 2004, J. Phys. Chem. A, 108, 6908

Zhao, Y., \& Truhlar, D. G. 2008, Theor. Chem. Acc., 120, 215

Zuckerman, B., Morris, M., Palmer, P., \& Turner, B. E. 1972, ApJ, 173, L125 


\section{Appendix A: New estimation of the cracking patterns of $\mathrm{CH}_{3} \mathrm{NCH}_{2}$}

Since the National Institute of Standards and Technology (NIST)

Chemistry Webbook has no records for the mass specta of $\mathrm{CH}_{3} \mathrm{NCH}_{2}$, we list our experimental values in the Table A.1.

Table A.1. Signal intensity of QMS normalized to the highest peak of $\mathrm{CH}_{3} \mathrm{NC}, \mathrm{CH}_{3} \mathrm{CN}$, and products after completing the reactions with $\mathrm{H}$ atoms.

\begin{tabular}{lcccccccc}
\hline \hline Mass & \multicolumn{2}{c}{$\mathrm{CH}_{3} \mathrm{NC}(\%)$} & \multicolumn{2}{c}{$\mathrm{CH}_{3} \mathrm{CN}(\%)$} & \multicolumn{2}{c}{$\mathrm{CH}_{3} \mathrm{NCH}_{2}(\%)$} & $\mathrm{CH}_{3} \mathrm{NHCH}_{3}(\%)$ \\
\hline & NIST & Work & NIST & Work & NIST & Work & NIST & Work \\
\hline M16 & 0 & 0 & 0 & 0 & 0 & 0 & 1 & 0 \\
M27 & 5 & 0 & 1 & 0 & - & 0 & 2 & 2 \\
M39 & 20 & 20 & 20 & 20 & - & 1 & 0 & 0 \\
M40 & 50 & 60 & 40 & 40 & - & 10 & 3 & 0.5 \\
M41 & 100 & 100 & 100 & 100 & - & 15 & 3 & 2 \\
M42 & 0 & 0 & 0 & 0 & - & 100 & 19 & 20 \\
M43 & 0 & 0 & 0 & 0 & - & 65 & 15 & 15 \\
M44 & 0 & 0 & 0 & 0 & 0 & 0 & 100 & 100 \\
M45 & 0 & 0 & 0 & 0 & 0 & 0 & 65 & 75 \\
\hline
\end{tabular}

Notes. Comparison between NIST webbook data and our experimental results.

\section{Appendix B: Spectroscopic and observational line parameters}

Tables B.1-B.4 give the spectroscopic and observational line parameters for the observed $\mathrm{CH}_{3} \mathrm{CN}, \mathrm{CH}_{3} \mathrm{NC}, \mathrm{C}_{2} \mathrm{H}_{5} \mathrm{NH}_{2}$, and $\mathrm{CH}_{3} \mathrm{NH}_{2}$ transitions.

Table B.1. Spectroscopic and observational line parameters for $\mathrm{CH}_{3} \mathrm{CN}$.

\begin{tabular}{|c|c|c|c|c|c|c|c|c|c|}
\hline $\begin{array}{l}\text { Freq. } \\
(\mathrm{GHz}) \\
(1)\end{array}$ & $\begin{array}{c}\text { Transition } \\
\text { (2) }\end{array}$ & $\begin{array}{l}E_{\text {up }} \\
(\mathrm{K}) \\
(3)\end{array}$ & $\begin{array}{c}A \\
\left(10^{-4} \mathrm{~s}^{-1}\right) \\
(4)\end{array}$ & $\begin{array}{c}v_{\mathrm{lsr}} \\
\left(\mathrm{km} \mathrm{s}^{-1}\right) \\
(5)\end{array}$ & $\begin{array}{c}T_{\text {peak }} \\
(\mathrm{K}) \\
(6)\end{array}$ & $\begin{array}{c}\Delta v_{1 / 2} \\
\left(\mathrm{~km} \mathrm{~s}^{-1}\right) \\
(7)\end{array}$ & $\begin{array}{c}W \\
\left(\mathrm{~K} \mathrm{~km} \mathrm{~s}^{-1}\right) \\
(8)\end{array}$ & $\begin{array}{c}N_{\text {up }} / g_{\text {up }} \\
\left(10^{10} \mathrm{~cm}^{-2}\right) \\
(9)\end{array}$ & $\begin{array}{c}\text { Comments } \\
\text { (10) }\end{array}$ \\
\hline 238.766 & $13_{9}-12_{9}$ & 658 & 4.21 & $56.2(0.3)$ & $0.8(0.1)$ & $8.0(0.7)$ & $7.1(0.5)$ & 1.7 & $\mathrm{D}$ \\
\hline 238.844 & $13_{8}-12_{8}$ & 537 & 5.03 & $54.3(0.2)$ & $1.0(0.1)$ & $7.9(0.4)$ & $8.8(0.4)$ & 3.6 & $\mathrm{D}$ \\
\hline 238.913 & $13_{7}-12_{7}$ & 430 & 5.75 & $55.9(0.2)$ & $1.7(0.1)$ & $6.9(0.4)$ & $12.2(1.0)$ & 4.4 & PB \\
\hline 238.972 & $13_{6}-12_{6}$ & 337 & 6.38 & $55.9(1.2)$ & $2.9(0.2)$ & $8.5(1.2)$ & $26.2(1.3)$ & 4.2 & PB \\
\hline 239.023 & $13_{5}-12_{5}$ & 259 & 6.91 & - & $\leq 3.60 .3$ & - & $\leq 40.0$ & $\leq 11.9$ & B \\
\hline 239.064 & $13_{4}-12_{4}$ & 195 & 7.35 & $55.7(1.1)$ & $3.5(0.2)$ & $8.4(0.3)$ & $31.5(1.0)$ & 8.8 & $\mathrm{D}$ \\
\hline 239.096 & $13_{3}-12_{3}$ & 145 & 7.69 & $55.4(0.6)$ & $4.6(1.2)$ & $8.2(1.2)$ & $40.7(5.5)$ & 5.4 & $\mathrm{D}$ \\
\hline 239.120 & $13_{2}-12_{2}$ & 109 & 7.93 & $55.9(1.2)$ & $4.7(0.4)$ & $8.3(1.2)$ & $41.4(3.5)$ & 10.8 & $\mathrm{D}$ \\
\hline 239.133 & $13_{1}-12_{1}$ & 87 & 8.07 & - & $\leq 6.0$ & - & $\leq 91.9$ & $\leq 23.4$ & B \\
\hline 239.138 & $13_{0}-12_{0}$ & 80 & 8.12 & - & $\leq 6.0$ & - & $\leq 91.9$ & $\leq 23.3$ & B \\
\hline
\end{tabular}

Notes. (1) Frequencies. (2) Transition. (3) Energy of the upper level. (4) Einstein coefficient. (5) Local Standard of Rest velocity (LSR velocity). (6) Brightness temperature. (7) Line width at half intensity. (8) Integrated intensities over the line profile. (9) Column densities of the upper state of the transition with respect to the rotational degeneracy. (10) Detected (D), blended (B), and partially blended (PB) lines are specified.

References. We used the spectroscopic data parameters from Boucher et al. (1977), Kukolich et al. (1973), Kukolich (1982), Anttila et al. (1993), Gadhi et al. (1995), and Cazzoli \& Puzzarini (2006). The spectroscopic data parameters are available in the JPL catalog (Pickett et al. 1998). 
Table B.2. Spectroscopic and observational line parameters for $\mathrm{CH}_{3} \mathrm{NC}$.

\begin{tabular}{|c|c|c|c|c|c|c|c|c|c|}
\hline $\begin{array}{c}\text { Freq. } \\
(\mathrm{GHz}) \\
(1)\end{array}$ & $\begin{array}{c}\text { Transition } \\
\text { (2) }\end{array}$ & $\begin{array}{c}E_{\text {up }} \\
(\mathrm{K}) \\
(3)\end{array}$ & $\begin{array}{c}A \\
\left(10^{-4} \mathrm{~s}^{-1}\right) \\
(4)\end{array}$ & $\begin{array}{c}v_{\mathrm{lsr}} \\
\left(\mathrm{km} \mathrm{s}^{-1}\right) \\
(5)\end{array}$ & $\begin{array}{c}T_{\text {peak }} \\
(\mathrm{K}) \\
(6) \\
\end{array}$ & $\begin{array}{c}\Delta v_{1 / 2} \\
\left(\mathrm{~km} \mathrm{~s}^{-1}\right) \\
(7)\end{array}$ & $\begin{array}{c}W \\
\left(\mathrm{~K} \mathrm{~km} \mathrm{~s}^{-1}\right) \\
(8)\end{array}$ & $\begin{array}{c}N_{\text {up }} / g_{\text {up }} \\
\left(10^{10} \mathrm{~cm}^{-2}\right) \\
(9)\end{array}$ & $\begin{array}{c}\text { Comments } \\
\text { (10) } \\
\end{array}$ \\
\hline 240.795 & $12_{9}-11_{9}$ & 647 & 5.16 & - & $\leq 0.8$ & - & $\leq 6.4$ & $\leq 1.4$ & ND \\
\hline 240.888 & $12_{8}-11_{8}$ & 527 & 6.57 & - & $\leq 0.8$ & - & $\leq 6.4$ & $\leq 2.2$ & ND \\
\hline 240.969 & $12_{7}-11_{7}$ & 421 & 7.80 & - & $\leq 0.8$ & - & $\leq 6.4$ & $\leq 1.8$ & ND \\
\hline 241.040 & $12_{6}-11_{6}$ & 329 & 8.88 & - & $\leq 1.3$ & - & $\leq 8.3$ & $\leq 1.1$ & B \\
\hline 241.100 & $12_{5}-11_{5}$ & 252 & 9.79 & - & $\leq 0.8$ & - & $\leq 6.4$ & $\leq 1.5$ & B \\
\hline 241.149 & $12_{4}-11_{4}$ & 188 & 10.54 & - & $\leq 0.8$ & - & $\leq 6.4$ & $\leq 1.4$ & B \\
\hline 241.187 & $12_{3}-11_{3}$ & 139 & 11.12 & - & $\leq 4.0$ & - & $\leq 32.1$ & $\leq 3.3$ & B \\
\hline 241.215 & $12_{2}-11_{2}$ & 103 & 11.53 & - & $\leq 4.0$ & - & $\leq 32.1$ & $\leq 6.3$ & B \\
\hline 241.231 & $12_{1}-11_{1}$ & 82 & 11.79 & - & $\leq 2.7$ & - & $\leq 21.7$ & $\leq 4.2$ & B \\
\hline 241.237 & $12_{0}-11_{0}$ & 75 & 11.87 & - & $\leq 2.7$ & - & $\leq 21.7$ & $\leq 4.1$ & B \\
\hline 100.490 & $5_{4}-4_{4}$ & 54 & 0.29 & - & $\leq 0.6$ & - & $\leq 4.2$ & $\leq 13.0$ & B \\
\hline 100.506 & $5_{3}-4_{3}$ & 194 & 0.52 & - & $\leq 0.1$ & - & $\leq 0.5$ & $\leq 0.4$ & ND \\
\hline 100.517 & $5_{2}-4_{2}$ & 127 & 0.68 & - & $\leq 0.1$ & - & $\leq 0.5$ & $\leq 0.7$ & ND \\
\hline 100.524 & $5,-4$ & 145 & 0.78 & - & $\leq 0.1$ & - & $\leq 0.5$ & $\leq 0.6$ & ND \\
\hline 100.527 & $5_{0}-4_{0}$ & 151 & 0.81 & - & $\leq 0.1$ & - & $\leq 0.5$ & $\leq 0.6$ & ND \\
\hline
\end{tabular}

Notes. (1) Frequencies. (2) Transition. (3) Energy of the upper level. (4) Einstein coefficient. (5) LSR velocity. (6) Brightness temperature. (7) Line width at half intensity. (8) Integrated intensities over the line profile. (9) Column densities of the upper state of the transition with respect to the rotational degeneracy. (10) Blended (B) and not detected (ND) lines are specified.

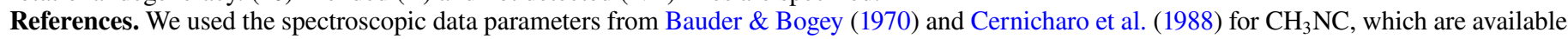
in the JPL catalog (Pickett et al. 1998).

Table B.3. Spectroscopic and observational line parameters for $\mathrm{C}_{2} \mathrm{H}_{5} \mathrm{NH}_{2}$.

\begin{tabular}{|c|c|c|c|c|c|c|c|c|c|}
\hline $\begin{array}{l}\text { Freq. } \\
(\mathrm{GHz}) \\
(1)\end{array}$ & $\begin{array}{c}\text { Transition } \\
\text { (2) }\end{array}$ & $\begin{array}{l}E_{\mathrm{up}} \\
(\mathrm{K}) \\
(3)\end{array}$ & $\begin{array}{c}A \\
\left(10^{-4} \mathrm{~s}^{-1}\right) \\
(4)\end{array}$ & $\begin{array}{c}v_{\mathrm{lsr}} \\
\left(\mathrm{km} \mathrm{s}^{-1}\right) \\
(5)\end{array}$ & $\begin{array}{c}T_{\text {peak }} \\
(\mathrm{K}) \\
(6)\end{array}$ & $\begin{array}{c}\Delta v_{1 / 2} \\
\left(\mathrm{~km} \mathrm{~s}^{-1}\right) \\
(7)\end{array}$ & $\begin{array}{c}W \\
\left(\mathrm{~K} \mathrm{~km} \mathrm{~s}^{-1}\right) \\
(8)\end{array}$ & $\begin{array}{c}N_{\mathrm{up}} / g_{\mathrm{up}} \\
\left(10^{10} \mathrm{~cm}^{-2}\right) \\
(9)\end{array}$ & $\begin{array}{c}\text { Comments } \\
\text { (10) }\end{array}$ \\
\hline 238.398619 & $15_{1.15}-14_{1.14}$ & 93 & 0.85 & - & $\leq 0.2$ & - & $\leq 1.7$ & $\leq 0.8$ & ND \\
\hline 239.037658 & $15_{0.15}-14_{0.14}$ & 93 & 0.85 & - & $\leq 0.2$ & - & $\leq 1.7$ & $\leq 0.8$ & ND \\
\hline 245.644356 & $15_{2.14}-14_{2.13}$ & 93 & 0.91 & - & $\leq 1.3$ & - & $\leq 10.2$ & $\leq 4.7$ & B \\
\hline
\end{tabular}

Notes. (1) Frequencies. (2) Transition. (3) Energy of the upper level. (4) Einstein coefficient. (5) LSR velocity. (6) Brightness temperature. (7) Line width at half intensity. (8) Integrated intensities over the line profile. (9) Column densities of the upper state of the transition with respect to the rotational degeneracy. (10) Blended (B) and not detected (ND) lines are specified.

References. The spectroscopic data parameters for $\mathrm{C}_{2} \mathrm{H}_{5} \mathrm{NH}_{2}$ come from Fischer \& Botskor (1982), Fischer \& Botskor (1984) and Apponi et al. (2008), and are available in the Cologne Database for Molecular Spectroscopy catalog (CDMS; Müller et al. 2005).

Table B.4. Spectroscopic and observational line parameters for $\mathrm{CH}_{3} \mathrm{NH}_{2}$.

\begin{tabular}{cccccccccc}
\hline \hline $\begin{array}{c}\text { Freq. } \\
(\mathrm{GHz})\end{array}$ & Transition & $\begin{array}{c}E_{\mathrm{up}} \\
(\mathrm{K})\end{array}$ & $\begin{array}{c}A \\
\left(10^{-4} \mathrm{~s}^{-1}\right)\end{array}$ & $\begin{array}{c}v_{\mathrm{lsr}} \\
\left(\mathrm{km} \mathrm{s}^{-1}\right) \\
(2)\end{array}$ & $\begin{array}{c}T_{\text {peak }} \\
(\mathrm{K}) \\
(6)\end{array}$ & $\begin{array}{c}\Delta v_{1 / 2} \\
\left(\mathrm{~km} \mathrm{~s}^{-1}\right) \\
(7)\end{array}$ & $\begin{array}{c}W \\
\left(\mathrm{~K} \mathrm{~km} \mathrm{~s}^{-1}\right) \\
(8)\end{array}$ & $\begin{array}{c}N_{\text {up }} / g_{\text {up }} \\
\left(10^{10} \mathrm{~cm}^{-2}\right) \\
(9)\end{array}$ & $\begin{array}{c}\text { Comments } \\
(10)\end{array}$ \\
\hline 239.023740 & $5_{2,0}-5_{1,1}$ & 48 & 0.60 & - & $\leq 3.5$ & - & $\leq 41.2$ & $\leq 174.2$ & B \\
239.209628 & $7_{2,2}-7_{1,3}$ & 76 & 0.63 & - & $\leq 2.6$ & - & $\leq 17.3$ & $\leq 17.0$ & B \\
241.209160 & $4_{2,1}-41,0$ & 37 & 0.59 & - & $\leq 4.0$ & - & $\leq 60.0$ & $\leq 321.1$ & B \\
242.262019 & $6_{2,3}-6_{1,2}$ & 61 & 0.64 & - & $\leq 0.4$ & - & $\leq 6.2$ & $\leq 7.1$ & B \\
242.961338 & $3_{2,0}-31,1$ & 29 & 0.55 & - & $\leq 0.3$ & - & $\leq 2.4$ & $\leq 17.8$ & ND \\
244.886901 & $5_{2,2}-5_{1,3}$ & 48 & 0.64 & - & $\leq 0.3$ & - & $\leq 2.4$ & $\leq 3.3$ & ND \\
\hline
\end{tabular}

Notes. (1) Frequencies. (2) Transition. (3) Energy of the upper level. (4) Einstein coefficient. (5) LSR velocity. (6) Brightness temperature. (7) Line width at half intensity. (8) Integrated intensities over the line profile. (9) Column densities of the upper state of the transition with respect to the rotational degeneracy. (10) Blended (B) and not detected (ND) lines are specified.

References. Spectroscopic data parameters come from Shimoda et al. (1954), Lide (1954, 1957), Nishikawa (1957), Takagi \& Kojima (1971), Ohashi et al. (1987), Kréglewski \& Wlodarczak (1992), Krȩglewski et al. (1992) and Ilyushin et al. (2005) and are available in the JPL catalog (Pickett et al. 1998). 